\title{
Updating Phospholipase A2 Biology
}

\author{
Makoto Murakami *(D, Hiroyasu Sato and Yoshitaka Taketomi
}

Laboratory of Microenvironmental and Metabolic Health Sciences, Center for Disease Biology and Integrative Medicine, Graduate School of Medicine, The University of Tokyo, Bunkyo-ku, Tokyo 113-8655, Japan; sato-hr@m.u-tokyo.ac.jp (H.S.); taketomiys@m.u-tokyo.ac.jp (Y.T.)

* Correspondence: makmurak@m.u-tokyo.ac.jp; Tel.: +81-3-5841-1431

Received: 24 September 2020; Accepted: 15 October 2020; Published: 19 October 2020

\begin{abstract}
The phospholipase $\mathrm{A}_{2}\left(\mathrm{PLA}_{2}\right)$ superfamily contains more than 50 enzymes in mammals that are subdivided into several distinct families on a structural and biochemical basis. In principle, $\mathrm{PLA}_{2}$ has the capacity to hydrolyze the $s n-2$ position of glycerophospholipids to release fatty acids and lysophospholipids, yet several enzymes in this superfamily catalyze other reactions rather than or in addition to the $\mathrm{PLA}_{2}$ reaction. $\mathrm{PLA}_{2}$ enzymes play crucial roles in not only the production of lipid mediators, but also membrane remodeling, bioenergetics, and body surface barrier, thereby

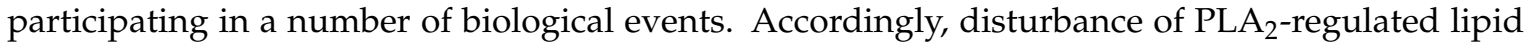
metabolism is often associated with various diseases. This review updates the current state of understanding of the classification, enzymatic properties, and biological functions of various enzymes belonging to the $\mathrm{PLA}_{2}$ superfamily, focusing particularly on the novel roles of $\mathrm{PLA}_{2} \mathrm{~S}$ in vivo.
\end{abstract}

Keywords: fatty acid; knockout mouse; lipid mediator; lipidomics; lysophospholipid; membrane; phospholipase $\mathrm{A}_{2}$; phospholipid

\section{Introduction}

Based on their structural relationships, the $\mathrm{PLA}_{2}$ superfamily is classified into several families, including the secreted $\mathrm{PLA}_{2}\left(\mathrm{sPLA}_{2}\right)$, cytosolic $\mathrm{PLA}_{2}\left(\mathrm{cPLA}_{2}\right), \mathrm{Ca}^{2+}$-independent PLA (iPLA 2 , also called patatin-like phospholipase (PNPLA)), platelet-activating factor acetylhydrolase (PAF-AH), lysosomal PLA 2 (LPLA 2 ), PLA/acyltransferase (PLAAT), $\alpha / \beta$ hydrolase (ABHD), and glycosylphosphatidylinositol (GPI)-specific PLA $_{2}$ families. PLA $_{2}$ s trigger the production of lipid mediators by releasing polyunsaturated fatty acids (PUFAs) and lysophospholipids from membrane phospholipids, and also participate in membrane homeostasis by altering phospholipid composition, in energy production by supplying fatty acids for $\beta$-oxidation, in generation of barrier lipids, or in fine-tuning of the microenvironmental balance between saturated and unsaturated fatty acids, among others. Many of the $\mathrm{PLA}_{2}$ enzymes recognize the differences in the fatty acyl and/or head group moieties of their substrate phospholipids, and several enzymes catalyze even non-PLA 2 reactions such as phospholipase $\mathrm{A}_{1}\left(\mathrm{PLA}_{1}\right)$, lysophospholipase, neutral lipid lipase, and transacylase reactions. The in vivo functions of individual $\mathrm{PLA}_{2} \mathrm{~s}$ rely on their enzymatic, biochemical, and cell biological properties, their tissue and cellular distributions, lipid composition in target membranes, the spatiotemporal availability of downstream lipid-metabolizing enzymes, or the presence of cofactor(s) that can modulate the enzymatic function, in various pathophysiological settings.

During the last two decades, the functions of various $\mathrm{PLA}_{2}$ s have been clarified by studies based on not only gene-manipulated (knockout and transgenic) mice but also human diseases caused by mutations of these enzymes. Here, we provide an overview of the biological roles of various $\mathrm{PLA}_{2} \mathrm{~S}$ and their underlying lipid pathways, focusing mainly on new findings in the last five years. Readers interested in older views as a starting point for further readings should refer to our current reviews 
describing the classification of the PLA 2 superfamily [1], those covering $\mathrm{PLA}_{2} \mathrm{~S}$ and lipid mediators broadly $[2,3]$, and those focusing on $\mathrm{sPLA}_{2} \mathrm{~s}[4-7]$.

\section{The sPLA2 Family}

\subsection{General Features}

The sPLA $\mathrm{A}_{2}$ family comprises low-molecular-mass, $\mathrm{Ca}^{2+}$-requiring enzymes with a conserved His-Asp catalytic dyad. There are 11 mammalian sPLA $_{2} \mathrm{~s}$ (IB, IIA, IIC, IID, IIE, IIF, III, V, X, XIIA, and XIIB), which are structurally subdivided into group I/II/V/X, group III, and group XII branches [8]. Individual $\mathrm{sPLA}_{2} \mathrm{~s}$ exhibit unique tissue or cellular distributions and enzymatic properties, suggesting their distinct biological roles. With regard to the substrate specificity of $\mathrm{sPLA}_{2} \mathrm{~s}$ as assessed by an assay using tissue-extracted natural membranes, $\mathrm{SPLA}_{2}-\mathrm{IB}$, -IIA and -IIE do not discriminate $s n-2$ fatty acid species, $\mathrm{SPLA}_{2}-\mathrm{V}$ tends to prefer those with a lower degree of unsaturation such as oleic acid (OA; C18:1) and linoleic acid (LA; C18:2), and sPLA 2 -IID, -IIF, -III and -X tend to prefer PUFAs such as $\omega 6$ arachidonic acid (AA; $\mathrm{C} 20: 4)$ and $\omega 3$ docosahexaenoic acid (DHA; $\mathrm{C} 22: 6)$. With regard to the polar head groups, sPLA 2 -III, $-\mathrm{V}$ and $-\mathrm{X}$ efficiently hydrolyze phosphatidylcholine (PC), while $\mathrm{sPLA}_{2} \mathrm{~S}$ in the group II subfamily hydrolyze phosphatidylethanolamine (PE) much better than PC. Individual $\mathrm{sPLA}_{2} \mathrm{~s}$ exert their specific functions by producing lipid mediators, by altering membrane phospholipid composition, by degrading foreign phospholipids in microorganisms or diets, or by modifying extracellular non-cellular lipid components such as lipoproteins, pulmonary surfactant or microvesicles in response to given microenvironmental cues. In certain cases, the sPLA ${ }_{2}$-binding protein PLA2R1 modulates the functions of $\mathrm{sPLA}_{2} \mathrm{~S}$ in either a positive or negative way. The pathophysiological roles of individual $\mathrm{sPLA}_{2} \mathrm{~s}$, as revealed by studies using $\mathrm{sPLA}_{2}$ knockout or transgenic mice in combination with comprehensive lipidomics, have been detailed in several recent reviews $[3,6,7,9]$.

\section{2. $s P L A_{2}-I B$ in Digestion and Immunity}

sPLA $_{2}$-IB (encoded by PLA2G1B in human) is synthesized as an inactive zymogen in the pancreas, and its $N$-terminal propeptide is cleaved by trypsin to yield an active enzyme in the duodenum [10]. The main role of sPLA $2-\mathrm{IB}$, a "pancreatic sPLA ${ }_{2}$ ", is to digest dietary and biliary phospholipids in the intestinal lumen. Perturbation of this process by gene disruption or pharmacological inhibition of sPLA $\mathrm{A}_{2}$-IB leads to resistance to diet-induced obesity, insulin resistance, and atherosclerosis due to decreased phospholipid digestion and absorption in the gastrointestinal tract [11-14]. Indeed, the human PLA2G1B gene maps to an obesity susceptibility locus [15]. These functions of sPLA $\mathrm{P}_{2}$-IB have been summarized in a recent review [16].

Beyond the well-established role of $\mathrm{SPLA}_{2}-\mathrm{IB}$ as a "digestive sPLA $\mathrm{A}_{2}$ " as outlined above, two recent studies have uncovered novel immunological functions of this sPLA 2 . Entwistle et al. [17] showed that $\mathrm{SPLA}_{2}-\mathrm{IB}$ is induced in a population of intestinal epithelial cells during helminth infection and is responsible for killing tissue-embedded larvae. Pla2g $1 b^{-/-}$mice fail to expel the intestinal helminths Heligmosomoides polygyrus and Nippostrongylus brasiliensis. Treatment of the parasite with sPLA 2 -IB hydrolyzes worm phospholipids (e.g., PE) and impairs development to the adult stage, suggesting that exposure to this enzyme in the intestine is an important mechanism of host-mediated defense against such parasites.

Pothlichet et al. [18] reported that sPLA 2 -IB is involved in $\mathrm{CD}^{+} \mathrm{T}$ cell lymphopenia in patients infected with human immunodeficiency virus (HIV). sPLA 2 -IB, in synergy with the HIV gp41 envelope protein, induces $\mathrm{CD} 4^{+} \mathrm{T}$ cell anergy, inhibiting the responses to IL-2, IL-4, and IL-7 as well as activation, proliferation, and survival of $\mathrm{CD}^{+} \mathrm{T}$ cells. Other $\mathrm{SPLA}_{2} \mathrm{~S}$ fail to display a similar function, implying a specific action of sPLA $A_{2}-\mathrm{IB}$. Importantly, the effects of $\mathrm{HIV}$ on $\mathrm{CD}^{+} \mathrm{T}$ cell anergy can be blocked by a sPLA 2 -IB-specific neutralizing antibody in vivo. Thus, the sPLA $\mathrm{A}_{2} \mathrm{IB} / \mathrm{gp} 41$ pair constitutes a new mechanism of immune dysfunction, although the cellular source of plasma sPLA 2 -IB in this context remains to be determined. 


\section{3. sPLA 2 -IIA in Host Defense, Sterile Inflammation, and Colon Cancer}

The best-known physiological function of sPLA 2 -IIA (encoded by PLA2G2A) is the degradation of bacterial membranes, particularly those in Gram-positive bacteria, thereby providing the first line of antimicrobial defense as a "bactericidal sPLA 2 " $[19,20]$. The ability of sPLA 2 -IIA to hydrolyze PE and phosphatidylglycerol, which are abundant in bacterial membranes, appears to fit with its anti-bacterial function. In the lungs of patients with cystic fibrosis, sPLA 2 -IIA-resistant Gram-negative Pseudomonas aeruginosa upregulates the expression of $\mathrm{sPLA}_{2}$-IIA, which then eradicates $\mathrm{sPLA}_{2}$-IIA-sensitive Gram-positive Staphylococcus aureus, allowing the former bacterium to become dominant within the niche [21]. Thus, sPLA 2 -IIA-mediated regulation of the bacterial community in the lung microenvironment crucially affects the pathology of cystic fibrosis.

sPLA $_{2}$-IIA is often referred to as an "inflammatory sPLA ${ }_{2}$ ", as its expression is induced by pro-inflammatory cytokines and lipopolysaccharide (LPS) [22]. Besides its action on bacterial membranes as noted above, sPLA 2 -IIA targets phospholipids in extracellular microvesicles (EVs), particularly those in extracellular mitochondria (organelles that have evolved from bacteria), which are released from activated platelets or leukocytes at sites of inflammation [23]. Hydrolysis of EV phospholipids by sPLA 2 -IIA results in the production of lipid mediators as well as the release of mitochondrial DNA as a danger-associated molecular pattern (DAMP) that contributes to amplification of inflammation. Specifically, the AA released from platelet-derived EVs by sPLA $\mathrm{AIA}_{2}$ is metabolized by platelet-type 12-lipoxygenase to 12-hydroxyeicosatetraenoic acid (HETE), which then acts on the BLT2 receptor on neutrophils facilitating the uptake of the EVs [24]. Thus, sPLA 2 -IIA is primarily involved in host defense by killing bacteria and triggering innate immunity, while over-amplification of the response leads to exacerbation of inflammation by hydrolyzing EVs (Figure 1). These dual functions of sPLA 2 -IIA were summarized in a recent review [25].

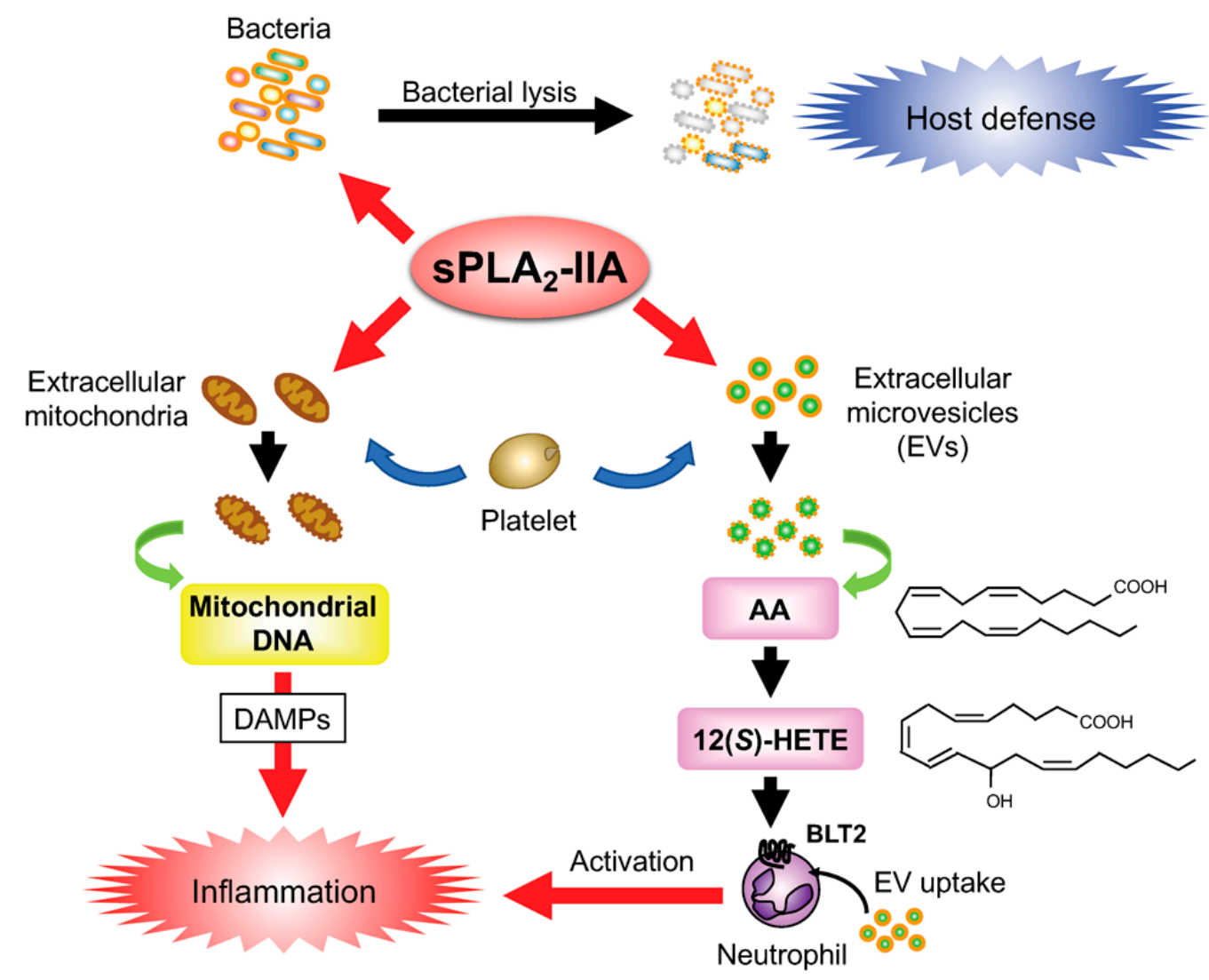

Figure 1. The roles of $\mathrm{SPLA}_{2}$-IIA in anti-bacterial defense by degrading bacterial membrane and in sterile inflammation by releasing pro-inflammatory eicosanoids from extracellular microvesicles (EVs) derived from inflammatory cells. 
sPLA ${ }_{2}$-IIA also appears to play a role in host defense against the malaria pathogen Plasmodium falciparum. Several sPLA ${ }_{2}$ s, including $\mathrm{SPLA}_{2}-\mathrm{IIF}, \mathrm{V}$ and $-\mathrm{X}$, which efficiently hydrolyze plasma lipoproteins to release free fatty acids, have the capacity to inhibit parasite growth in vitro, yet these $\mathrm{sPLA}_{2} \mathrm{~s}$ are undetectable in human plasma. sPLA 2 -IIA, though hardly hydrolyzing normal lipoproteins, is increased in the plasma of malaria patients and hydrolyzes "oxidized" lipoproteins to block Plasmodium growth [26]. Injection of recombinant sPLA 2 -IIA into Plasmodium-infected mice reduces the peak of parasitemia when the level of plasma peroxidation is increased during infection. Thus, malaria-induced oxidation of lipoproteins converts them into a preferential substrate for sPLA 2 -IIA, thus promoting its parasite-killing effect.

PLA2G2A-transgenic mice display notable skin abnormalities with hair loss and epidermal hyperplasia [27]. Using K14-driven, skin-specific PLA2G2A-transgenic mice, Chovatiya et al. [28] recently demonstrated that sPLA ${ }_{2}$-IIA promotes hair follicle stem cell proliferation through JNK

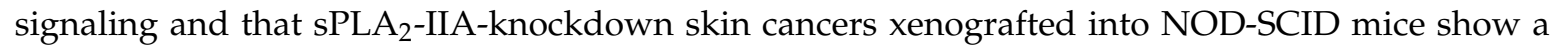
concomitant reduction of tumor volume and decreased JNK signaling. Kuefner et al. [29] showed that PLA2G2A-transgenic mice are protected from diet-induced obesity and become more prone to adipocyte browning with increased expression of thermogenic markers. However, since C57BL/6 mice do not express $\mathrm{sPLA}_{2}$-IIA endogenously due to a frameshift mutation in the Pla2g2a gene [30], the physiological relevance of these results obtained from transgenic overexpression of $\mathrm{SPLA}_{2}$-IIA in this mouse strain should be interpreted with caution. The increased energy expenditure in PLA2G2A-transgenic mice might be simply due to their lack of fur, which results in increased heat dissipation from the body surface. Indeed, transgenic mice overexpressing sPLA $\mathrm{AIF}_{2}$ or $\mathrm{sPLA}_{2}-\mathrm{X}$ are also furless and lean [31]. Studies using a series of $\mathrm{sPLA}_{2}-\mathrm{knockout}$ mice have suggested that sPLA - IIF and sPLA - IID are the main endogenous regulators of skin homeostasis and adipocyte browning, respectively, as described below.

Although sPLA ${ }_{2}$-IIA has been identified as a genetic modifier of mouse intestinal tumorigenesis [30], the underlying mechanism has long remained unclear. Schewe et al. [32] recently provided a potential mechanism by which sPLA 2 -IIA, expressed by Paneth cells in the small intestine, suppresses colon cancer. In a normal state, sPLA 2 -IIA inhibits Wnt signaling through intracellular activation of Yap1. Upon inflammation, sPLA $\mathrm{A}_{2}$-IIA is secreted into the intestinal lumen, where it promotes inflammation through prostaglandin $(\mathrm{PG}) \mathrm{E}_{2}$ synthesis via the PLA2R1-CPLA $2 \alpha$ pathway and Wnt signaling. Transgenic overexpression of sPLA $\mathrm{A}_{2}$-IIA delays recovery from colonic inflammation but decreases colon cancer susceptibility due to perturbation of its homeostatic Wnt-inhibitory function. Thus, this trade-off effect could provide a mechanism whereby $\mathrm{SPLA}_{2}$-IIA acts as a genetic modifier of colonic inflammation and cancer. However, the inflammatory sPLA ${ }_{2}$-IIA-PLA2R1-CPLA $2 \alpha-\mathrm{PGE}_{2}$ signaling axis proposed in this study may require further clarification, since contrary to this hypothesis, there is ample evidence that ${ }_{C P L A} \alpha$ and its product $\mathrm{PGE}_{2}$ contribute to attenuation of colitis and promotion of colon cancer [33]. Other factors, such as intestinal dysbiosis due to loss of sPLA $\mathrm{A}_{2}$-IIA, might primarily underlie the increased susceptibility to gastrointestinal cancer-a possibility that awaits future study.

Apart from its potential signaling role, PLA2R1 acts as a clearance receptor for sPLA $2 \mathrm{~s}[8,34]$. In a model of experimental autoimmune myocarditis induced by immunizing BALB/c mice, a strain possessing a normal Pla2g2a gene, with the murine $\alpha$-myosin heavy chain [30], PLA2R1 deficiency markedly increases sPLA 2 -IIA and -IB proteins (but not mRNAs) in the myocardium, probably as a result of their impaired clearance [35]. In the affected myocardium, PLA2R1 and these two sPLA ${ }_{2} \mathrm{~S}$ are localized in $\alpha-\mathrm{SMA}^{+}$myofibroblasts and infiltrating neutrophils, respectively. The Pla $2 \mathrm{r}^{-/-}$ myocardium shows increased areas of inflammatory cell infiltration, accompanied by an increase in $\mathrm{PGE}_{2}$, which promotes IL-23-induced expansion of Th17 cells. Thus, it appears that this increase of sPLA ${ }_{2}$-IIA and -IB proteins due to their defective clearance contributes to exacerbation of autoimmune myocarditis, although it remains unclear whether these $\mathrm{PLA}_{2} \mathrm{~s}$ act through $\mathrm{PGE}_{2}$ synthesis or through other mechanisms, whether some other $\mathrm{SPLA}_{2} \mathrm{~s}$ that are expressed in the myocardium and have the capacity to bind to PLA2R1 are also involved in this process, or whether the effect of PLA2R1 ablation is $\mathrm{SPLA}_{2}$-independent. 


\section{4. sPLA 2 -IID in Immunosuppression, Host Defense, and Adaptive Thermogenesis}

sPLA $_{2}$-IID (encoded by PLA2G2D), constitutively expressed in dendritic cells (DCs) in lymphoid organs, is a "resolving $\mathrm{SPLA}_{2}$ " that attenuates DC-mediated adaptive immunity by hydrolyzing PE to mobilize anti-inflammatory $\omega 3$ PUFAs and their metabolites such as DHA-derived resolvin D1 [36]. Pla2g $2 d^{-/-}$mice exhibit more severe contact hypersensitivity (Th1 response) and psoriasis (Th17 response), accompanied by marked reductions of $\omega 3$ PUFAs and their metabolites in the draining lymph nodes and spleen. On the other hand, $\mathrm{Pla} 2 \mathrm{~g} 2 \mathrm{~d}^{-/-}$mice are protected against skin cancer likely because of the enhanced anti-tumor immunity in association with increased IFN- $\gamma^{+} \mathrm{CD} 8^{+} \mathrm{T}$ cells [37]. The immunosuppressive role of sPLA 2 -IID in the Th1, Th2, and Th17 responses was detailed in a recent review [9].

Chronic low-grade inflammation is associated with age-related immune dysfunction in the lung, and is countered by enhanced expression of pro-resolving/anti-inflammatory factors to maintain tissue homeostasis. Vijay et al. [38] reported that sPLA 2 -IID with an anti-inflammatory property contributes to worse outcomes in mice infected with severe acute respiratory syndrome coronavirus (SARS-CoV) or influenza A virus. Strikingly, Pla $2 g_{2} d^{-/-}$mice are highly protected against SARS-CoV infection, with enhanced migration of DCs to the lymph nodes, augmented anti-viral T cell responses, reduced lung damage, and increased survival. In the context of the current worldwide SARS-CoV2 pandemic, inhibition of $\mathrm{sPLA}_{2}$-IID in the lungs of older patients with severe respiratory infections could be a potentially attractive therapeutic intervention for restoration of immune function.

w3 PUFAs confer health benefits by preventing inflammation and obesity and by increasing thermogenesis in brown and beige adipocytes. sPLA $_{2}$-IID is constitutively expressed in M2 macrophages in white adipose tissue (WAT) and downregulated during obesity [39]. Global or macrophage-specific sPLA 2 -IID deficiency decreases energy expenditure and thermogenesis by preventing adipocyte browning, thus exacerbating diet-induced obesity, insulin resistance, and WAT inflammation [39]. In WAT, PLA2G2D constitutively supplies a pool of $\omega 3$ PUFAs, which acts on the PUFA receptor GPR120 and thereby promotes the thermogenic program as a "thermogenic sPLA 2 ". Importantly, dietary supplementation with $\omega 3$ PUFAs normalizes the metabolic derangement in Pla2g $2 d^{-/-}$mice. These findings highlight the contribution of the macrophage-driven PLA2G2D-w3 PUFA axis to metabolic health (Figure 2). Possibly in relation to this, a polymorphism in the human PLA2G2D gene is linked to body weight changes in patients with chronic lung disease [40].

\subsection{SPLA $A_{2}$-IIE and SPLA $A_{2}$-IIF in the Skin}

sPLA $_{2}$-IIE (encoded by PLA2G2E) is hardly detected in human tissues, whereas sPLA 2 -IIE instead of $\mathrm{SPLA}_{2}$-IIA is upregulated in several mouse tissues under inflammatory or other conditions. For instance, sPLA 2 -IIE is highly upregulated in adipocytes during diet-induced obesity [41], and is expressed in hair follicles in correlation with the growth phase of the hair cycle [42]. sPLA 2 -IIE hydrolyzes PE without apparent fatty acid selectivity in lipoproteins and hair follicles, and Pla $2 g 2 e^{-/-}$ mice display modest metabolic and hair follicle abnormalities.

sPLA $_{2}$-IIF (encoded by PLA2G2F) is an "epidermal sPLA ${ }_{2}$ " expressed in the suprabasal epidermis and upregulated by the Th17 cytokines IL-17A and IL-22 in psoriatic skin [31]. sPLA 2 -IIF preferentially hydrolyzes PUFA-containing plasmalogen-type PE to produce lysoplasmalogen (plasmalogen-type lysophosphatidylethanolamine; P-LPE), which in turn promotes epidermal hyperplasia. Accordingly, Pla2g $2 f^{--}$mice are protected against psoriasis and skin cancer, while Pla2g2f-transgenic mice spontaneously develop psoriasis-like skin and are more susceptible to skin cancer [31]. Overall, two skin sPLA 2 , sPLA 2 -IIE in the outer root sheath of hair follicles and sPLA $\mathrm{A}_{2}$-IIF in epidermal keratinocytes, play non-redundant roles in distinct compartments of mouse skin, underscoring the functional diversity of multiple $\mathrm{PLA}_{2} \mathrm{~s}$ in the coordinated regulation of skin homeostasis and diseases. The roles of sPLA 2 -IIE and -IIF were detailed in a recent review [9]. 


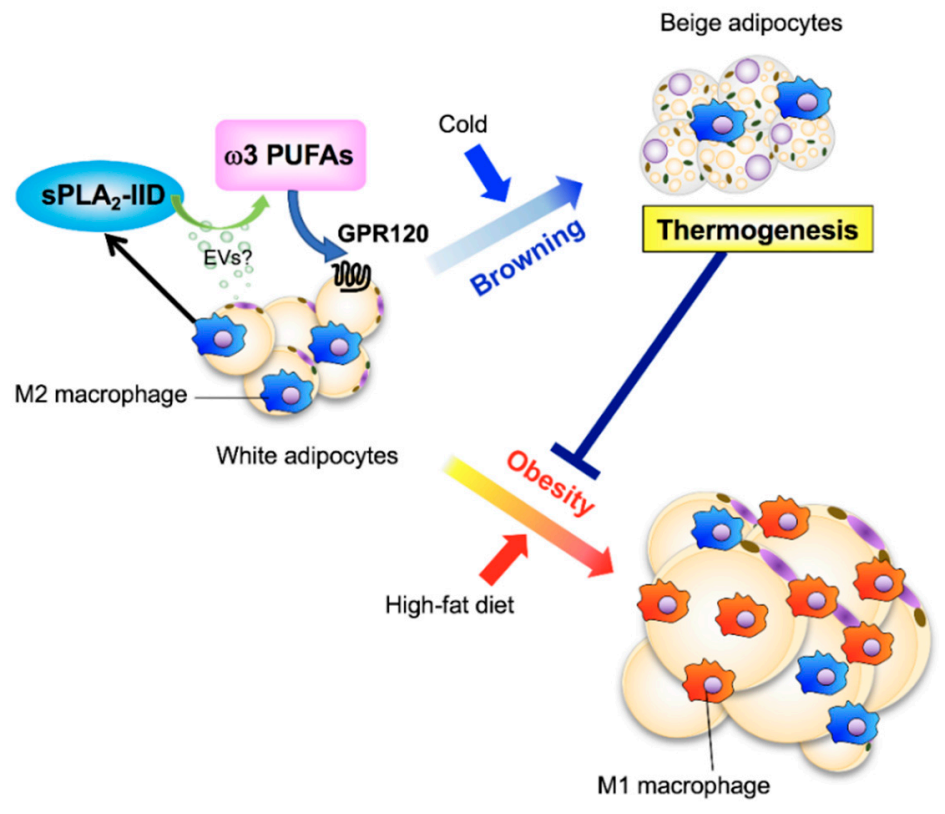

Figure 2. The role of sPLA 2 -IID expressed in M2 macrophages in adipocyte browning and adaptive thermogenesis. sPLA 2 -IID releases $\omega 3$ PUFAs, which then act on GPR120 to drive the thermogenic and anti-inflammatory programs toward metabolic health. Impairment of this sPLA 2 -IID-driven lipid pathway leads to impaired thermogenesis and exacerbated diet-induced obesity.

\section{6. sPLA $A_{2}$-III in Male Reproduction, Anaphylaxis, and Colonic Diseases}

sPLA $_{2}$-III (encoded by PLA2G3) consists of three domains, in which the central sPLA domain $_{2}$ similar to bee venom group III sPLA ${ }_{2}$ is flanked by large and unique $N$ - and $C$-terminal domains [43]. The enzyme is processed to the $\mathrm{PPLA}_{2}$ domain-only form that retains full enzymatic activity [44]. sPLA 2 -III is expressed in the epididymal epithelium and acts on immature sperm cells passing through the epididymal duct in a paracrine manner to allow sperm membrane phospholipid remodeling, a process that is prerequisite for sperm motility [45]. Homozygous and even heterozygous Pla2g3-deficient sperm have impaired motility and thereby fail to fertilize oocytes, leading to hypofertility. In the context of allergy, sPLA 2 -III secreted from immature mast cells is functionally coupled with lipocalin-type $\mathrm{PGD}_{2}$ synthase (L-PGDS) in neighboring fibroblasts to supply a microenvironmental pool of $\mathrm{PGD}_{2}$, which in turn acts on the $\mathrm{PGD}_{2}$ receptor DP1 on mast cells to promote their proper maturation [46]. Accordingly, mice lacking sPLA 2 -III, as well as those lacking L-PGDS or DP1, have immature mast cells and display reduced local and systemic anaphylactic responses.

Several lines of evidence suggest a potential link between sPLA 2 -III and the development of colon cancer. For instance, sPLA ${ }_{2}$-III-transfected colon cancer cells xenografted into nude mice show increased growth [47], higher expression of sPLA 2 -III in human colorectal cancer is positively correlated with a higher rate of lymph node metastasis and shorter survival [48], and polymorphisms in the human PLA2G3 gene are significantly associated with a higher risk of colorectal cancer [49]. Importantly, $\mathrm{Pla}_{\mathrm{g}} \mathrm{3}^{-/-}$mice are resistant to several models of colon cancer [50]. Furthermore, Pla $2 \mathrm{~g}^{-1-}$ mice are less susceptible to colitis, with lower expression of pro-inflammatory and pathogenic Th17 cytokines and higher expression of epithelial barrier genes [50], implying that amelioration of colonic inflammation by sPLA 2 -III ablation underlies the protective effect against colon cancer. The Pla $2 \mathrm{~g}^{-/-}$ colon displays significant reduction of several lysophospholipids including lysophophatidic acid (LPA) and lysophosphatidylinositol (LPI) [50], which may promote colon inflammation or cancer through their receptors $\mathrm{LPA}_{2}$ and GPR55, respectively [51,52]. Overall, these results establish a role for sPLA 2 -III in the aggravation of colonic inflammation and cancer and point to $\mathrm{PLA}_{2}-\mathrm{III}$ as a novel druggable target for colorectal diseases. The biological roles of sPLA ${ }_{2}$-III were summarized in a recent review [9]. 


\section{7. sPLA $A_{2}-V$ in Obesity, Type-2 Immunity, and Aortic Protection}

Although $\mathrm{sPLA}_{2}-\mathrm{V}$ (encoded by PLA2G5) was previously thought to be a regulator of AA metabolism [53,54], it has become obvious that this sPLA 2 has a preference for phospholipids bearing sn-2 fatty acids with a lower degree of unsaturation. Transgenic overexpression of sPLA $2-\mathrm{V}$ results in neonatal death due to a respiratory defect attributable to the ability of $\mathrm{SPLA}_{2}-\mathrm{V}$ to potently hydrolyze dipalmitoyl-PC, a major component of lung surfactant [55]. Mice that are transgenic for other sPLA $2 \mathrm{~S}$ do not exhibit such a phenotype, implying the particular ability of sPLA $2-\mathrm{V}$ to hydrolyze PC with $s n-2$ palmitic acid (C16:0) in the lung microenvironment. sPLA $2-\mathrm{V}$ is markedly induced in adipocytes during obesity as a "metabolic sPLA 2 " and hydrolyzes PC in hyperlipidemic LDL to release OA and LA, which counteract adipose tissue inflammation and thereby ameliorate metabolic disorders [41]. Impairment of this process in Pla $2 \mathrm{~g}^{-/-}$mice leads to exacerbation of diet-induced obesity and insulin intolerance, accompanied by elevated phospholipid levels in plasma LDL. This phenotype is reminiscent of clinical evidence that a PLA2G5 polymorphism is associated with plasma LDL levels in patients with type 2 diabetes [56] and that the levels of PLA2G5 mRNA expression in WAT are inversely correlated with plasma LDL levels in obese subjects [41].

$\mathrm{sPLA}_{2}-\mathrm{V}$ is a "Th2-prone sPLA ${ }_{2}$ " induced in M2 macrophages by the Th2 cytokines IL-4 and IL-13 and promotes Th2-driven pathologies such as asthma. Gene ablation of sPLA $2-V$ perturbs proper polarization and function of M2 macrophages in association with decreased Th2 immunity [57]. Pla2g5 $5^{-/}$mice show reduced activation of type 2 innate lymphoid cells (ILC2) and infiltration of eosinophils in the lung following repetitive inhalation of the fungal allergen Alternaria Alternata [58]. Adoptive transfer experiments have revealed the contribution of $\mathrm{SPLA}_{2}-\mathrm{V}$ expressed in both macrophages and non-hematopoietic cells (probably bronchial epithelial cells) to the pathology. Lipidomics analysis has demonstrated reduction of OA and LA in the lung and macrophages in Pla2g $5^{-/-}$mice. Exogenous administration of these unsaturated fatty acids to Pla2g5 $5^{-/-}$mice restores IL-33-induced inflammation and ILC2 expansion, implying that macrophage-associated sPLA $2-V$ contributes to type 2 immunity by promoting ILC2 activation though the release of OA and LA. The biological roles of $\mathrm{sPLA}_{2}-\mathrm{V}$ in asthma were summarized in a recent review [59]. Probably because of the alteration in the macrophage phenotype, $\mathrm{Pla} 2 \mathrm{~g}^{-/-}$macrophages have a reduced ability to phagocytose extracellular materials, thereby being more susceptible to fungal infection and arthritis due to defective clearance of hazardous fungi and immune complexes, respectively [60,61]. Likewise, Pla $g 5^{-/-}$mice suffer from more severe lung inflammation caused by bacterial infection [62], which could also be explained by poor clearance of these microbes by alveolar macrophages. Additionally, local generation of LPE in the plasma membrane by sPLA $2-\mathrm{V}$ may also contribute to macrophage phagocytosis [63].

Aortic dissection is a life-threatening aortopathy involving separation of the aortic wall. Since aortic dissection occurs suddenly without preceding clinical signs and current treatment strategies are limited mainly to antihypertensive agents and emergency surgery, biomarkers that can predict fragility and/or therapeutic targets for stabilization of the aortic wall are needed in order to improve patient outcomes. Behind its proposed role in atherosclerosis development [64], sPLA $2-\mathrm{V}$ is a primary "endothelial $\mathrm{sPLA}_{2}$ " that protects against aortic dissection by endogenously mobilizing vasoprotective fatty acids [65]. Global and endothelial cell-specific deletion of sPLA $2-V$ leads to dissection of the thoracic ascending aorta shortly after infusion of angiotensin II (AT-II). In the AT-II-treated aorta, endothelial sPLA $2-\mathrm{V}$ mobilizes $\mathrm{OA}$ and LA, which attenuate endoplasmic reticulum (ER) stress and increase the expression of lysyl oxidase, an enzyme that crosslinks extracellular matrix (ECM) proteins, thereby stabilizing the ECM in the aorta. Of note, dietary supplementation with OA and LA reverses the increased susceptibility of Pla $2 \mathrm{~g}^{-/-}$mice to aortic dissection. These findings reveal an unexplored functional link between sPLA 2 -driven phospholipid metabolism and aortic stability (Figure 3), possibly contributing to the development of improved diagnostic and/or therapeutic strategies for preventing aortic dissection. Importantly, this work provides in vivo relevance for the actions of this sPLA $\mathrm{A}_{2}$ that had been proposed by several in vitro studies: (i) it releases OA and LA in preference to PUFAs, (ii) it preferentially acts on membranes of agonist-stimulated rather than quiescent cells, and (iii) it is 
retained on the cell surface through binding to heparan sulfate proteoglycan. Furthermore, this avenue of cardiovascular research has revealed a potential mechanism that could underlie the benefits of the olive oil-rich (i.e., OA-rich) Mediterranean diet in terms of cardiovascular health.

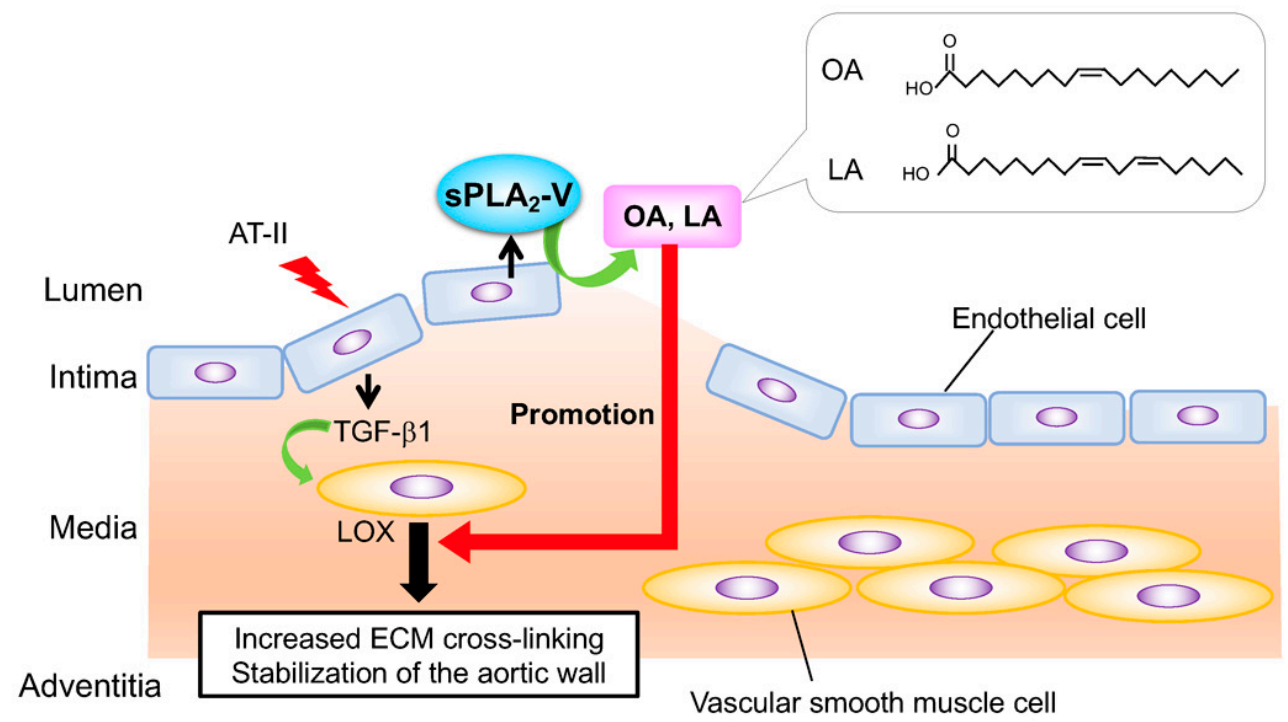

Figure 3. The role of endothelial $\mathrm{sPLA}_{2}-\mathrm{V}$ in aortic stability. $\mathrm{sPLA}_{2}-\mathrm{V}$ is a major $\mathrm{sPLA}_{2}$ isoform expressed in aortic endothelial cells (ECs) and is largely retained on the luminal surface of the aortic endothelium likely through binding to heparin sulfate proteoglycans. Endothelial sPLA $2-\mathrm{V}$ acts on membrane phospholipids of AT-II-activated ECs to mobilize oleic acid (OA) and linoleic acid (LA), which in turn promote AT-II-induced upregulation of lysyl oxidase (LOX) that facilitates ECM crosslinking, thereby stabilizing the aortic wall. Impairment of this $\mathrm{sPLA}_{2}-\mathrm{V}$-driven lipid pathway leads to increased susceptibility to aortic dissection.

\section{8. sPLA $A_{2}-\mathrm{X}$ in Sperm Activation, Colitis, and Asthma}

Among the mammalian sPLA $\mathrm{S}_{2}$, $\mathrm{SPLA}_{2}-\mathrm{X}$ (encoded by PLA2G10) has the highest activity on PC leading to release of fatty acids, particularly PUFAs, and is activated by cleavage of the $N$-terminal propeptide by furin-type convertases [66]. In mice, $\mathrm{sPLA}_{2}-\mathrm{X}$ is expressed abundantly in the testis and gastrointestinal tract and to a much lesser extent in the lung, whereas its expression in other tissues is very low. In the process of reproduction, $\mathrm{SPLA}_{2} \mathrm{X}$ is secreted from the acrosomes of activated spermatozoa and hydrolyzes sperm membrane phospholipids to release DHA, docosapentaenoic acid (DPA, C22:5), and LPC, which facilitate in vitro fertilization with oocytes [33,67]. Pla2g10-/spermatozoa also show impairment of the late phase of the progesterone-induced acrosome reaction ex vivo [68]. Thus, the two particular $\mathrm{sPLA}_{2} \mathrm{~S}$ expressed in male reproductive organs, i.e., sPLA $\mathrm{A}_{2}$-III secreted from the epididymal epithelium (see above) and sPLA $\mathrm{A}_{2}-\mathrm{X}$ secreted from sperm acrosomes, act as "reproductive $\mathrm{SPLA}_{2} \mathrm{~s}$ " to coordinately regulate male reproduction.

$\mathrm{sPLA}_{2}-\mathrm{X}$ is expressed abundantly in colorectal epithelial and goblet cells and plays a protective role against colitis by mobilizing anti-inflammatory w3 PUFAs such as EPA and DHA [33]. Accordingly, Pla2g $10^{-/-}$mice display more severe epithelial damage and inflammation with reduction of colonic $\omega 3$ PUFAs rather than $w 6$ AA in a colitis model, while PLA2G10-transgenic mice exhibit global anti-inflammatory phenotypes in association with elevation of systemic levels of $\omega 3$ PUFAs and their metabolites [33]. Supplementation with exogenous EPA restores the colitis phenotype in Pla2g10 mice. Furthermore, Pla2g10-/- mice have lower fecal LA levels [69], suggesting that gastrointestinal $\mathrm{sPLA}_{2}-\mathrm{X}$ may have a role in the digestion of dietary and biliary phospholipids (as in the case of $\mathrm{sPLA}_{2}$-IB) or, alternatively, contribute to shaping of the gut microbiota. The latter possibility may help to explain the fact that $\mathrm{Pla} 2 \mathrm{~g} 10^{-/-}$mice display certain inflammatory, cardiovascular, and metabolic phenotypes that are not necessarily consistent among different laboratories [69-72]. 
$\mathrm{sPLA}_{2}-\mathrm{X}$ is expressed constitutively in the airway epithelium and increased after antigen challenge in mice, and also in asthma patients. Pla $2 \mathrm{~g} 10^{-/-}$mice are protected from antigen-induced asthma, with marked reductions of airway hyperresponsiveness, eosinophil and T cell trafficking to the airways, airway occlusion, secretion of type- 2 cytokines, generation of antigen-specific IgE, and synthesis of pulmonary eicosanoids including cysteinyl leukotrienes [73]. Further, Pla $2 g 10^{-/-}$mice have reduced IL-33 levels and fewer ILC2 cells in the lung, lower IL-33-induced IL-13 expression in mast cells, and a marked reduction in both the number of newly recruited macrophages and the M2 polarization of these macrophages in the lung [74]. These results indicate that $\mathrm{SPLA}_{2}-\mathrm{X}$ serves as a key regulator of both innate and adaptive immune responses to allergens. Interestingly, as in the case of bee venom group III sPLA $\mathrm{A}_{2}$ that elicits strong type- 2 immune responses, exogenous administration of sPLA $2-\mathrm{X}$ serves as an adjuvant, leading to augmented type-2 immune responses with increased airway hypersensitivity and antigen-specific type-2 inflammation following peripheral sensitization and subsequent airway challenge with the antigen [75]. The biological roles of $\mathrm{PLAA}_{2}-\mathrm{X}$ in asthma were detailed in a recent review [76].

\section{The sPLA 2 Family}

\subsection{General Features}

The cytosolic PLA $2\left(\mathrm{CPLA}_{2}\right)$ family comprises 6 isoforms $(\alpha-\zeta)$, among which $\mathrm{CPLA} 2 \beta, \delta, \varepsilon$, and $\zeta$ map to the same chromosomal locus [77]. There is structural similarity between the cPLA 2 and iPLA $_{2}$ families in that their catalytic domain is characterized by a three-layer $\alpha / \beta / \alpha$ architecture employing a conserved Ser/Asp catalytic dyad [78,79]. It appears that these two families were evolved from a common ancestral gene, with the $\mathrm{PLA}_{2}$ family emerging from the $\mathrm{iPLA} \mathrm{A}_{2}$ family at the branching point of vertebrates in correlation with the development of the lipid mediator signaling pathways. Enzymes belonging to the $\mathrm{CPLA}_{2}$ family are characterized by the presence of a C2 domain at their $N$-terminal region, with the exception of $\mathrm{cPLA}_{2} \gamma$ in which this domain is absent. The $\mathrm{C} 2$ domain is responsible for the $\mathrm{Ca}^{2+}$-dependent association with membranes. Herein, we will overview several recent topics for $\mathrm{cPLA}_{2} \alpha$ as well as potential functions of other $\mathrm{CPLA}_{2}$ isoforms.

\subsection{New Insights into $\mathrm{cPL} A_{2} \alpha$}

$\mathrm{cPLA}_{2} \alpha$ (group IVA PLA 2 ; encoded by PLA2G4A) is the best known PLA 2 that plays a central role in stimulus-coupled AA metabolism. $\mathrm{CPLA}_{2} \alpha$ is the only $\mathrm{PLA}_{2}$ that shows a striking substrate specificity for phospholipids containing AA (and also those containing EPA, if this $\omega 3$ PUFA is present in cell membranes at substantial levels). Upon cell activation, $\mathrm{CPLA}_{2} \alpha$ translocates from the cytosol to the perinuclear (particularly Golgi) membranes in response to an increase in the $\mu \mathrm{M}$ range of cytosolic $\mathrm{Ca}^{2+}$ concentration, and is maximally activated by phosphorylation through mitogen-activated protein kinases and other kinases $[80,81]$. The phosphoinositide $\mathrm{PIP}_{2}$ modulates the subcellular localization and activation of $\mathrm{cPLA}_{2} \alpha$ [82]. The regulatory roles of $\mathrm{cPLA}_{2} \alpha$ in eicosanoid generation in various pathophysiological events, as revealed by biochemical analyses as well as by studies using Pla $2 \mathrm{~g} 4 a^{-/-}$ mice, have been well summarized in several elegant reviews $[83,84]$.

By means of comprehensive lipidomics, Slatter et al. [85] showed that human platelets acutely increase mitochondrial energy generation following stimulation and that the substrates for this, including multiple fatty acids and oxidized species that support energy generation via $\beta$-oxidation, are exclusively provided by $\mathrm{cPLA}_{2} \alpha$. This implies that $\mathrm{cPLA}_{2} \alpha$ is a central regulator of both lipid mediator generation and energy flux in human platelets and that acute phospholipid membrane remodeling is required to support energy demands during platelet activation.

Ceramide-1-phosphate (C1P), a sphingolipid-derived bioactive lipid, directly binds to and activates $\mathrm{cPLA}_{2} \alpha$ to stimulate the production of eicosanoids in vitro [86], but in vivo evidence for this event has been lacking. Recently, MacKnight et al. [87] addressed this issue by generating knockin mice in which endogenous $\mathrm{CPLA}_{2} \alpha$ is replaced with a mutant form having an ablated C1P-interaction site. 
In a skin wound healing model, wound maturation, rather than wound closure, is enhanced in the mutant $\mathrm{CPLA}_{2} \alpha$-knockin mice compared to control mice. Primary dermal fibroblasts from the knockin mice show substantially increased collagen deposition and migration. The knockin mice also show an altered eicosanoid profile, with a reduction of $\mathrm{PGE}_{2}$ and $\mathrm{TXB}_{2}$ (a stable end-metabolite of $\mathrm{TXA}_{2}$ ) as well as an increase of HETE species, which enhances the migration and collagen deposition of dermal fibroblasts. This gain-of-function role for the mutant $\mathrm{CPLA}_{2} \alpha$ is associated with its relocalization to the cytoplasm and cytoplasmic vesicles. These findings clarify the key mechanisms by which wound healing is regulated by $\mathrm{cPLA}_{2} \alpha-\mathrm{C} 1 \mathrm{P}$ interaction in vivo and provide insight into the roles of $\mathrm{CPLA}_{2} \alpha$ and eicosanoids in orchestrating wound repair.

Chao et al. [88] reported that the $\mathrm{C} 2$ domain in $\mathrm{CPLA}_{2} \alpha$ interacts with the CARD domain in mitochondrial antiviral signaling protein (MAVS), boosting NF-kB-driven transcriptional programs that promote experimental autoimmune encephalomyelitis, a model of multiple sclerosis. cPLA $2 \alpha$ recruitment to MAVS also disrupts MAVS-hexokinase 2 interactions, decreasing hexokinase activity and the production of lactate involved in the metabolic support of neurons. These findings define a novel role of $\mathrm{CPLA}_{2} \alpha$ in driving pro-inflammatory astrocyte activities in cooperation with MAVS through protein-protein interaction in the context of neuroinflammation. It remains unknown whether some cPLA $\mathrm{P}_{2} \alpha$-driven lipid mediators are involved in this process.

Oncogenic PIK3CA (encoding a PI3K isoform) results in an increase of AA and eicosanoids, thus promoting cell proliferation to beyond a cell-autonomous degree. Mechanistically, mutant PIK3CA drives a multimodal signaling network involving mTORC2-PKC $\zeta$-mediated activation of $\mathrm{cPLA}_{2} \alpha$ [89]. Notably, inhibition of $\mathrm{CPLA}_{2} \alpha$ acts synergistically with a fatty acid-free diet to restore immunogenicity and selectively reduce mutant PIK3CA-induced tumorigenicity. This reveals an important role for activated PI3K signaling in regulation of AA metabolism, highlighting a targetable metabolic vulnerability that depends largely on dietary fat restriction.

\section{3. $c P L A_{2} \beta$ Fusion Protein in Carcinoma Cell Proliferation and Survival}

cPLA $2 \beta$ (group IVB PLA ${ }_{2}$; encoded by PLA2G4B) displays PLA 1, PLA $_{2}$ and more potent lysophospholipase activities in vitro. A kinetic study has demonstrated that $c \mathrm{PLA}_{2} \beta$ associates with a membrane surface that is rich in phosphoinositides when intracellular $\mathrm{Ca}^{2+}$ is low, whereas it moves to a cardiolipin-rich membrane such as the mitochondrial membrane when intracellular $\mathrm{Ca}^{2+}$ rises. Among three splice variants termed $\mathrm{CPLA}_{2} \beta 1, \beta 2$ and $\beta 3$, only the $\beta 3$ form is identified as an endogenous protein and is constitutively associated with mitochondrial and early endosomal membranes [90].

Cheng et al. [91] reported that JMJD7-PLA2G4B, a read-through fusion gene formed by splicing of the neighboring JMJD7 (jumonji domain containing 7) and PLA2G4B genes, is expressed in human squamous cell carcinoma (HNSCC), as well as several other cancers. Ablation of JMJD7-PLA2G4B, but not JMJD7 or PLA2G4B alone, significantly inhibits proliferation of SCC cells by promoting G1 arrest and increases starvation-induced cell death. These findings provide a novel insight into the oncogenic control of JMJD7-PLA2G4B in HNSCC cell proliferation and survival and suggest that this fusion protein may serve as an important therapeutic target and prognostic marker for HNSCC development and progression. $\mathrm{cPLA}_{2} \beta$ has also been implicated in age-related changes in phospholipids and decreased energy metabolism in monocytes [92]. However, it remains unknown whether certain lipid metabolites generated by $\mathrm{cPLA}_{2} \beta$ would be involved in these events.

\section{4. $c P L A_{2} \gamma$ in Lipid Droplet Formation}

Human cPLA $2 \gamma$ (group IVC PLA 2 ; encoded by PLA2G4C), lacking the $\mathrm{C} 2$ domain characteristic of the $\mathrm{CPLA}_{2}$ family, is $C$-terminally farnesylated, is tightly associated with membranes, and possesses lysophospholipase and transacylase activities in addition to $\mathrm{PLA}_{2}$ activity [93]. Several lines of evidence suggest that $\mathrm{CPLA}_{2} \gamma$ acts mainly as a CoA-independent transacylase, transferring a fatty acid from one phospholipid to the other phospholipid, in cells $[94,95] . \mathrm{CPLA}_{2} \gamma$ is widely expressed in human tissues 
with a tendency for higher expression in the heart and skeletal muscle, whereas its expression in most mouse tissues is very low, making it difficult to address the in vivo roles of cPLA $2 \gamma$ using a knockout strategy. Exceptionally, mouse $\mathrm{CLAA}_{2} \gamma$ is highly expressed in oocytes during the stage of germinal vesicle breakdown, when it dynamically relocates from the cortex to the nuclear envelope, suggesting its possible role in nuclear membrane remodeling in developing oocytes [96].

Lipid droplet (LD) accumulation in hepatocytes is a typical characteristic of steatosis. Hepatitis C virus (HCV) infection, one of the risk factors related to hepatic steatosis, induces LD accumulation in human hepatocytes. $\mathrm{cPLA}_{2} \gamma$ has been identified as a host factor upregulated by HCV infection and involved in HCV replication, where it promotes LD biogenesis and HCV assembly [97,98]. cPLA $2 \gamma$, through the domain around the amino acid residues 260-292, is tightly associated normally with ER membranes and relocated into LDs. Importantly, PLA2G4C knockdown hampers LD formation upon HCV stimulation, while PLA2G4C overexpression leads to LD formation in hepatocytes and enhances LD accumulation in the liver of mice fed a high-fat diet, suggesting its potential role in fatty liver disease.

\section{5. $c P L A_{2} \delta$ in Psoriasis}

$\mathrm{cPLA}_{2} \delta$ (group IVD PLA 2 ; encoded by PLA2G4D) was first identified as a keratinocyte-specific $\mathrm{CPLA}_{2}$ isoform that is induced during psoriasis and releases LA selectively [99]. However, subsequent studies showed that the $\mathrm{PLA}_{2}$ activity of $\mathrm{cPLA}_{2} \delta$ is much weaker than that of $\mathrm{CPLA}_{2} \alpha$ [77] and that its $\mathrm{PLA}_{1}$ activity is superior to its PLA 2 activity [90]. Cheung et al. [100] recently demonstrated the expression of $\mathrm{cPLA}_{2} \delta$ in psoriatic mast cells, and found unexpectedly that its activity is extracellular. IFN- $\alpha$-stimulated mast cells release exosomes, which transfer cytoplasmic cPLA ${ }_{2} \delta$ to neighboring Langerhans cells expressing CD1a, which present lipid antigens to T cells. Thus, the exosome-mediated transfer of $\mathrm{cPLA}_{2} \delta$ from mast cells to Langerhans cells leads to the generation of neolipid antigens and subsequent recognition by lipid-specific CD1a-reactive T cells, inducing the production of IL-22 and IL-17A. These data offer an alternative model of psoriasis pathogenesis in which lipid-specific CD1a-reactive $T$ cells contribute to psoriatic inflammation, suggesting that $\mathrm{CPLA}_{2} \delta$ inhibition or CD1a blockade may have potential for treatment of psoriasis. However, given that CD1a is present in humans but not in mice, and that $\mathrm{CPLA}_{2} \delta$ is located mainly in epidermal keratinocytes, the regulatory roles of $\mathrm{cPLA}_{2} \delta$ in psoriatic skin require further exploration.

\section{6. $c P L A_{2} \varepsilon$ as an N-Acyltransferase for N-Acylethanolamine Biosynthesis}

$N$-acylethanolamines (NAEs) represent a group of endocannabinoid lipid mediators, including arachidonoylethanolamine (also known as anandamide; AEA), which acts on the endocannabinoid receptors $\mathrm{CB} 1$ or $\mathrm{CB} 2$, and palmitoyletanolamine (PEA) and oleoylethanolamine (OEA), which act on the nuclear receptor PPAR $\alpha$ or through other mechanisms. The biosynthesis of NAEs, particularly PEA and OEA, occurs in two steps; transfer of $s n-1$ saturated or monounsaturated fatty acid of PC to the amino group of PE by $N$-acyltransferases to generate $N$-acyl-PE (NAPE), followed by hydrolysis mainly by NAPE-specific phospholipase D (NAPE-PLD) to give rise to NAEs [101]. There are two types of $N$-acyltransferase, i.e., $\mathrm{Ca}^{2+}$-dependent and -independent enzymes. Recently, it has been shown that

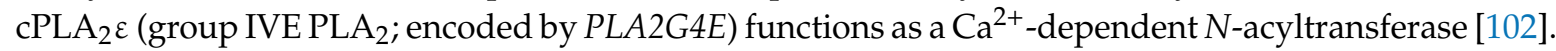
In response to $\mathrm{Ca}^{2+}$ ionophore stimulation, $\mathrm{HEK} 293$ cells overexpressing $\mathrm{CPLA} \mathrm{A}_{2} \varepsilon$ produce various NAPE and NAE species, accompanied by concomitant decreases in PE and PC and increases in LPE and LPC, indicating that $\mathrm{CPLA}_{2} \varepsilon$ produces NAPEs by utilizing the diacyl- and plasmalogen types of PE as acyl acceptors and the diacyl types of PC and PE as acyl donors [103] (Figure 4A). The activity of $\mathrm{CPLA}_{2} \varepsilon$ is markedly enhanced by the presence of phosphatidylserine (PS) or other anionic phospholipids, and $\mathrm{CPLA}_{2} \varepsilon$ largely co-localizes with PS in the plasma membrane and organelles involved in the endocytic pathway $[104,105]$. This localization might be related to the observation that $\mathrm{cPLA}_{2} \varepsilon$ drives recycling through the clathrin-independent endocytic route [106]. 
(A)

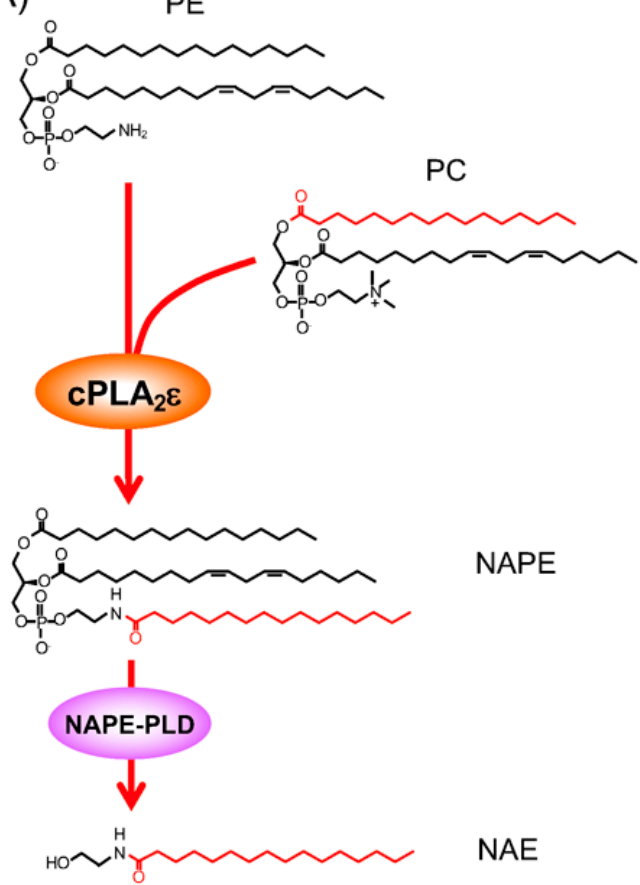

(B)
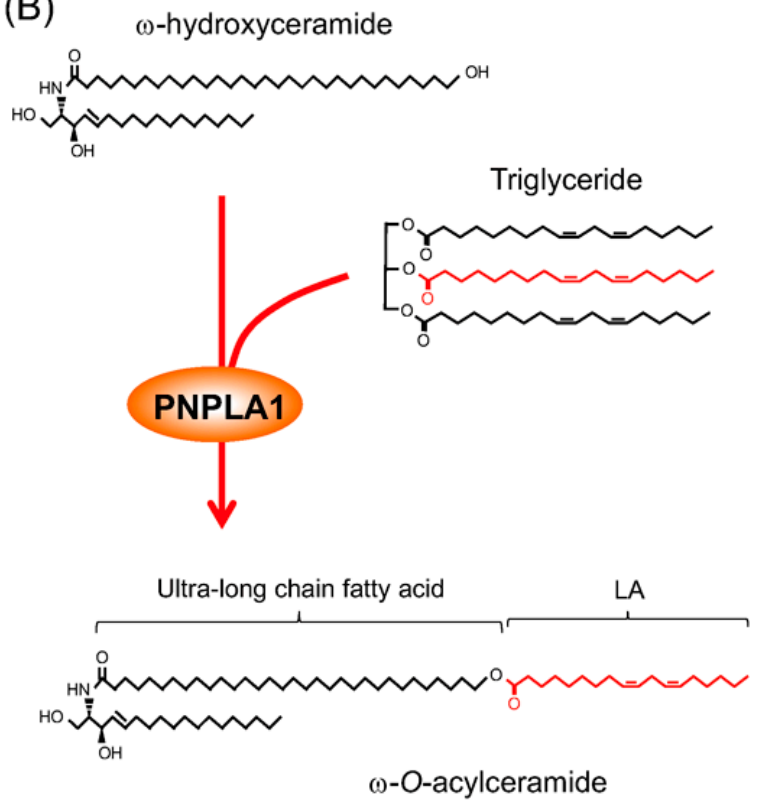

$\omega$-O-acylceramide

Figure 4. Examples of $\mathrm{PLA}_{2}$ enzymes that have unique enzymatic activity. (A) $c P L A_{2} \varepsilon$ catalyzes an $N$-acyltransferase reaction, transferring the $s n-1$ fatty acid of $P C$ to the amino group of $P E$ to produce NAPE, which is then converted to NAE by NAPE-PLD. (B) PNPLA1 acts as a unique transacylase, transferring LA from triglyceride to $\omega$-hydroxyceramide to give rise to $\omega$-O-acylceramide, which is essential for skin barrier function.

However, it still remains to be determined whether $\mathrm{CPLA}_{2} \varepsilon$ indeed contributes to NAPE and NAE biosynthesis under certain in vivo conditions. Since genetic deletion or pharmacological inhibition of NAPE-PLD disturbs lipid metabolism in the liver, intestine, and adipose tissue [107], as well as emotional behavior [108], it is tempting to speculate that $\mathrm{CPLA}_{2} \varepsilon$, which lies upstream of NAPE-PLD for NAE biosynthesis, may also participate in these events to improve metabolism and neuronal functions. The potential neuroprotective role of $\mathrm{CPLA}_{2} \varepsilon$ is supported by the association between reduced expression of $\mathrm{CPLA}_{2} \varepsilon$ and dementia, where adenoviral overexpression of $\mathrm{CPLA}_{2} \varepsilon$ in hippocampal neurons completely restores cognitive deficits in the elderly APP/PS1 mouse, a model of Alzheimer's disease [109].

\section{7. $c P L A_{2} \zeta$ in Myocardial Mitochondria}

The observation that multiple fatty acids are non-selectively released from $\mathrm{Ca}^{2+}$-stimulated Pla2g $4 a^{-/-}$lung fibroblasts, an event that is suppressed by $\mathrm{CPLA}_{2} \alpha$ inhibitors, suggests that other $\mathrm{CPLA}_{2}$ isoform(s) might contribute to this event. This fatty acid release and $\mathrm{PGE}_{2}$ production by Pla2g $4 a^{-1-}$ fibroblasts depend on $\mathrm{CPLA}_{2} \zeta$ (group IVF PLA ${ }_{2}$, encoded by PLA2G4F) [110]. In response to ionomycin, $\mathrm{CPLA}_{2} \zeta$ translocates to ruffles and dynamic vesicular structures, while $\mathrm{CPLA}_{2} \alpha$ translocates to the Golgi and ER, suggesting distinct mechanisms of regulation for the two enzymes.

Moon et al. [111] reported that mitochondria isolated from human heart contain at least two $\mathrm{PLA}_{2} \mathrm{~S}-\mathrm{CPLA}_{2} \zeta$ and iPLA $_{2} \gamma-$ of which $\mathrm{CPLA}_{2} \zeta$ mediates $\mathrm{Ca}^{2+}$-activated release of AA from mitochondria in normal heart. The AA pool mobilized by $\mathrm{CPLA}_{2} \zeta$ is preferentially channeled into cytochrome $\mathrm{P} 450$ epoxygenases for the synthesis of epoxyeicosatrienoic acids (EETs), which have a protective effect against heart failure. In contrast, in the failing heart, $\mathrm{iPLA}_{2} \gamma$ mainly mobilizes mitochondrial AA, which preferentially couples with lipoxygenases for the synthesis of toxic HETEs that open mitochondrial permeability transition pores, leading to further progression of heart failure. 
These results reveal an unexplored biological role of $\mathrm{CPLA}_{2} \zeta$ as well as $\mathrm{PPLA}_{2} \gamma$ (see below) in the myocardium, although confirmation using Pla2g $4 f$-null mice will be required.

\section{The iPLA $2 /$ PNPLA Family}

\subsection{General Features}

The human genome encodes $9 \mathrm{Ca}^{2+}$-independent $\mathrm{PLA}_{2}\left(\mathrm{iPLA}_{2}\right)$ enzymes. These enzymes are now more generally known as patatin-like phospholipase domain-containing lipases (PNPLA1-9), since all members in this family share a patatin domain, which was initially discovered in patatin $\left(\mathrm{iPLA}_{2} \alpha\right)$, a potato protein $[2,112]$. Unlike the $\mathrm{CPLA}_{2}$ family, which is present only in vertebrates, the iPLA 2 /PNPLA family is widely expressed in many eukaryotes including yeast, ameba, nematode, fly and vertebrates. iPLA 2 /PNPLA isoforms display lipid hydrolase or transacylase/acyltransferase activities with specificities for diverse lipids such as phospholipids, neutral lipids, sphingolipids, and retinol esters. In principle, enzymes with a large and unique $N$-terminal region (PNPLA6 9) act mainly on phospholipids as PLA $1, \mathrm{PLA}_{2}$ or lysophospholipases, whereas those lacking the $N$-terminal domain (PNPLA1 5) act on neutral lipids as lipases or transacylases. Analysis of gene disruption or mutation of the iPLA $\mathrm{A}_{2} /$ PNPLA enzymes in mice and humans have provided valuable insights into their physiological roles in homeostatic lipid metabolism that are fundamental for life. Since there have been many excellent reviews on this enzyme family $[2,3,112,113]$, we will herein highlight several recent topics that shed further light on the pathophysiological roles of this enzyme family.

\section{2. $i P L A_{2} \beta$ in Neurodegeneration and Hepatic Steatosis}

$\mathrm{iPLA}_{2} \beta$ (also known as group VIA PLA ${ }_{2}$; encoded by PLA2G6) is the only iPLA $A_{2}$ isoform that acts primarily as a PLA $A_{2}$ with poor fatty acid selectivity $[114,115]$. Different splice variants of iPLA $A_{2} \beta$ are associated with the plasma membrane, mitochondria, ER, and the nuclear envelope. Although iPLA $A_{2} \beta$ lacks a transmembrane domain, it has putative protein-interaction motifs such as ankyrin repeats, which are capable of interacting with multiple cognate receptor proteins, and a calmodulin-binding site, which interacts with the inhibitory calmodulin. The crystal structure of iPLA $\beta$ reveals a dimer formation of the catalytic domains, which are surrounded by ankyrin repeats that adopt an outwardly flared orientation, poised to interact with membrane proteins [116]. The closely integrated active sites are positioned for cooperative activation and internal transacylation. The structure also suggests allosteric inhibition by calmodulin, where a single calmodulin molecule interacts with two catalytic domains, altering the conformation of the dimer interface and active sites.

The roles of $\mathrm{iPLA}_{2} \beta$ in male fertility, neuronal disorders, metabolic diseases, and inflammation, among others, have been studied in a number of Pla2g6 knockout, knockdown, and overexpression studies and are well summarized in recent reviews $[113,117]$. In particular, the roles of iPLA $A_{2} \beta$ in neuronal function have received extensive attention, since numerous mutations of the PLA2G6 gene have been discovered in patients with neurodegenerative disorders such as infantile neuroaxonal dystrophy (INAD) and Parkinson's disease [118]. In fact, $\mathrm{PPLA}_{2} \beta$ is also referred to as the parkinsonism-associated protein PARK14, mutations of which are associated with impaired $\mathrm{Ca}^{2+}$ signaling in dopaminergic neurons [119].

Three recent studies using mutant flies have provided novel insights into the regulatory roles of iPLA $\beta$ in the brain in the context of Parkinson's disease with $\alpha$-synucleinopathy. Kinghorn et al. [120] reported that knockout of the PLA2G6 gene in Drosophila results in reduced survival, locomotor deficits, and organismal hypersensitivity to oxidative stress, accompanied by mitochondrial abnormalities and increased lipid peroxidation levels. Inhibition of lipid peroxidation partially rescues the locomotor abnormalities and mitochondrial membrane potential caused by iPLA $\beta$ deficiency. Lin et al. [121] showed that the loss of iPLA ${ }_{2} \beta$ causes an increase of brain ceramide, leading to lysosomal stress and neurodegeneration. iPLA $2 \beta$ binds to the retromer subunits Vps35 and Vps26 and enhances their function to promote protein and lipid recycling. Loss of iPLA $A_{2} \beta$ impairs retromer function resulting in a progressive increase of ceramide, thus inducing a positive feedback loop that 
affects membrane fluidity and impairs retromer function and neuronal function. Mori et al. [122] showed that iPLA $\beta$ deficiency in Drosophila results in defective neurotransmission during the early developmental stages and progressive cell loss throughout the brain, including degeneration of the dopaminergic neurons. In the brain, $\mathrm{iPLA}_{2} \beta$ loss results in shortening of the acyl-chain length of phospholipids, resulting in membrane lipid disequilibrium and thereby ER stress. Introduction of the mitochondria-ER contact site-resident protein C19orf12, another causal gene for Parkinson's disease, in PLA2G6-deficient flies rescues the phenotypes associated with altered lipid composition, ER stress, and neurodegeneration. Moreover, the acceleration of $\alpha$-synuclein aggregation by iPLA $\mathrm{A}_{2} \beta$ deficiency is suppressed by administration of LA, which corrects the brain phospholipid composition. Thus, membrane remodeling by $\mathrm{iPLA}_{2} \beta$ is required for the survival of dopaminergic neurons and $\alpha$-synuclein stability.

The roles of $\mathrm{PLA}_{2} \beta$ in phospholipid remodeling in the context of hepatic lipid metabolism have recently been studied using Pla $2 g 6^{-/-}$mice. iPLA $2 \beta$ deficiency attenuates obesity and hepatic steatosis in $o b / o b$ mice through hepatic fatty-acyl phospholipid remodeling [123]. Aging sensitized by $\mathrm{iPLA}_{2} \beta$ deficiency induces liver fibrosis and intestinal atrophy involving suppression of homeostatic genes and alteration of intestinal lipids and bile acids [124]. Pla $2 \mathrm{~g}^{-/-}$mice fed a high-fat diet show attenuation of hepatic steatosis through correction of defective phospholipid remodeling [125]. Lastly, Pla2g $6^{-/-}$mice fed a methionine/choline-deficient diet do not show correction of this defect, but the hepatocellular injury is attenuated via inhibition of lipid uptake genes [126].

\section{3. $i P L A_{2} \gamma$ in Bioenergetics and Signaling}

$\mathrm{iPLA}_{2} \gamma$ (also known as group VIB PLA 2 , encoded by PNPLA8) displays PLA $_{2}$ activity, but acts as a PLA 1 toward phospholipids bearing sn-2 PUFA $[127,128]$. Accordingly, hydrolysis of PUFA-bearing phospholipids by iPLA $2 \gamma$ typically gives rise to 2-lysophospholipids (having a PUFA at the $s n-2$ position) rather than 1-lysophospholipids (having a saturated or monounsaturated acid at the sn-1 position). Pnpla $8^{-/-}$mice display multiple bioenergetic and neuronal dysfunctions, including growth retardation, kyphosis, muscle weakness with atrophy of myofilaments, cold intolerance, reduced exercise endurance, increased mortality due to cardiac stress, resistance to diet-induced obesity and insulin resistance, performance deficits in spatial learning and memory, and abnormal mitochondrial function with a dramatic decrease in fatty acid $\beta$-oxidation and oxygen consumption [129]. The alterations in myocardial and hippocampal cardiolipin content and composition indicate that $\mathrm{PLA}_{2} \gamma$ is involved in cardiolipin remodeling. These features of $\mathrm{Pnpla}^{-1-}$ mice are reminiscent of those seen in patients with Barth syndrome, a disease caused by mutations in the human TAZ gene, which encodes tafazzin, a mitochondrial transacylase required for cardiolipin remodeling [130]. Moreover, loss-of-function variants of the human PNPLA8 gene recapitulate the mitochondriopathy observed in Pnpla $^{-1-}$ mice [131].

$\mathrm{iPLA}_{2} \gamma$ also participates in the generation of lipid mediators under certain conditions. Pnpla $^{-/-}$mice display reduced ADP- or collagen-stimulated $\mathrm{TXA}_{2}$ generation by platelets ex vivo and show prolonged bleeding time and reduced pulmonary thromboembolism in vivo [132]. Cardiomyocyte-specific deletion of iPLA $2 \gamma$ decreases infarct size upon ischemia/reperfusion, with reduction of oxygenated metabolites of $\omega 3$ and $\omega 6$ PUFAs including PGs, HETEs, and hydroxy-DHAs [133]. iPLA $2 \gamma$ releases 9-hydroxyoctadecenoic acid (9-HODE), an oxygenated metabolite of LA, from cardiolipin, integrating mitochondrial bioenergetics and signaling [134]. Heart failure-induced activation of iPLA $2 \gamma$ leads to mitochondrial generation of HETEs that open the mitochondrial permeability transition pore, thus further amplifying myocardial damage [111]. Phospholipids bearing sn-2 AA are cleaved by the $\mathrm{PLA}_{1}$ activity of $\mathrm{PPLA}_{2} \gamma$ to give rise to 2-arachidonoyl-lysophospholipids, which are then oxygenized directly by cyclooxygenase- 2 or 12-lipoxygenase for conversion to eicosanoid-esterified lysophospholipids [134,135]. The generation of eicosanoid-esterified lysophospholipids is attenuated by the absence of $\mathrm{iPLA}_{2} \gamma$, underscoring an $\mathrm{iPLA}_{2} \gamma$-initiated pathway generating new classes of lipid metabolites with potential signaling functions. 


\subsection{PNPNA6 and PNPLA7 as Lysophospholipases}

PNPLA6 $\left(\mathrm{iPLA}_{2} \delta\right.$ ) and its closest paralog PNPLA7 (iPLA ${ }_{2} \theta$ ) have a lysophospholipase activity that cleaves LPC to yield fatty acid and glycerophosphocholine (GPC) $[136,137]$. Counterparts of these enzymes in yeast and fly act as a phospholipase B, which converts PC to GPC by liberating both $s n-1$ and $s n-2$ fatty acids. PNPLA6, also referred to as neuropathy target esterase (NTE), was originally identified as a target enzyme for the poisonous effect of organophosphates, which cause a severe neurological disorder characterized by degeneration of long axons in the spinal cord and peripheral nerves, leading to paralysis of the lower limbs [138]. In cultured renal cells, the production of GPC, an osmoprotective metabolite, is enhanced by PNPLA6 overexpression and is diminished by its siRNA knockdown or its inhibitor organophosphate [139]. Global Pnpla6 ${ }^{-/-}$mice die in utero due to placental defects, while neuron-specific Pnpla $^{-/-}$mice exhibit progressive neuronal degeneration, leading to prominent neuronal pathology in the hippocampus and thalamus and also defects in the cerebellum [140,141]. Neuronal absence of PNPLA6 results in disruption of the ER, vacuolation of nerve cell bodies and abnormal reticular aggregates, and sustained elevation of PC over many months is accompanied by progressive degeneration and massive swelling of axons in the sensory and motor spinal tracts and worsening hindlimb dysfunction [142]. In humans, PNPLA6 mutations near the catalytic site cause a severe motor neuron disease characterized by progressive spastic paraplegia and distal muscle wasting [143] as well as childhood blindness with retinal degeneration, including Leber congenital amaurosis, Oliver McFarlane syndrome, and Boucher-Neuhäuser syndrome [144]. Although the in vivo role of PNPLA7, also known as NTE-related esterase (NRE), is still unknown, it is downregulated by insulin in WAT [136] and interacts with LDs through its catalytic domain [145], suggesting its metabolic role.

\subsection{PNPLA2 and PNPLA3 in Triglyceride Metabolism}

Although PNPLA2 and PNPLA3 correspond to iPLA $\zeta$ and iPLA $A_{2} \varepsilon$, respectively, according to the $\mathrm{PLA}_{2}$ classification, the latter names are not used here because these enzymes act essentially as neutral lipid lipases, but not as phospholipases. PNPLA2 is upregulated, while PNPLA3 is downregulated, upon starvation, and vice versa upon feeding, indicating that these two closely related lipases are nutritionally regulated in a reciprocal way [146]. PNPLA2, more generally known as adipose triglyceride lipase (ATGL), is a major lipase that hydrolyzes triglycerides in LDs to release fatty acids for $\beta$-oxidation-coupled energy production, a process known as lipolysis [147]. Genetic deletion or mutation of PNPLA2 leads to accumulation of triglycerides in multiple tissues leading to heart failure, while conferring protection from fatty liver and glucose intolerance, likely because these mice are able to utilize glucose but not free fatty acids as a fuel $[148,149]$. PNPLA2 deficiency also protects against cancer-associated cachexia by preventing fat loss [150]. The fatty acids released from LDs by PNPLA2 act as endogenous ligands for the nuclear receptor PPAR $\alpha$ or PPAR $\delta$, which drives energy consumption [151,152]. In addition, the AA released from triglycerides by PNPLA2-driven lipolysis is utilized for eicosanoid generation in certain situations [153]. The activity of PNPLA2 is regulated positively by ABHD5 (also known as CGI-58) and negatively by perilipin, G0S2 and mysterin, which modulate the accessibility of PNPLA2 to LDs [152,154]. Adipocyte-specific G0S2-transgenic mice show attenuated lipolysis and adipocyte hypertrophy, accompanied by a reduced hepatic triglyceride level and increased insulin sensitivity [155], thus recapitulating the phenotypes observed in Pnpla2-/mice [149]. Mutations in the human PNPLA2 gene cause Chanarin-Dorfman syndrome, a condition in which triglycerides are stored abnormally in the body [156]. ABHD5 mutations also cause a similar neutral lipid storage disease but also additionally cause ichthyosis [157], likely because ABHD5 acts as a cofactor for not only PNPLA2-mediated lipolysis, but also PNPLA1-driven $\omega$-O-acylceramide synthesis in the skin (see below). The regulatory mechanisms and metabolic roles of PNPLA2 have been detailed in other elegant reviews $[158,159]$.

Mutations in the human PNPLA3 gene are highly associated with non-alcoholic fatty liver disease (NAFLD) and steatohepatitis (NASH) [160]. However, Pnpla3 ${ }^{-/-}$mice do not display a fatty liver 
phenotype [161], whereas PNPLA3 ${ }^{\mathrm{I1}}{ }^{15 \mathrm{M}}$ knockin mice develop hepatic steatosis [162], illustrating the complexity of the regulatory roles of PNPLA3 in hepatic lipid metabolism. PNPLA3 reportedly acts as an acyltransferase that alters the fatty acid composition of triglycerides [163], as a transacylase that promotes the transfer of PUFAs from triglycerides to phospholipids in hepatic LDs [164], or as a retinyl-palmitate lipase in hepatic stellate cells to fine-tune the plasma levels of retinoids, which might influence the differentiation of stellate cells to myofibroblasts [165]. It has now become recognized that PNPLA3 functions primarily as a triglyceride lipase and that I158M mutation leads to loss of function. Importantly, PNPLA3, and PNPLA $3^{\mathrm{I} 158 \mathrm{M}}$ to an even greater extent, strongly interact with ABHD5, a cofactor for PNPLA2, thereby interfering with the lipolytic activity of PNPLA2 [166,167]. Overexpression of PNPLA3 ${ }^{1158 \mathrm{M}}$ greatly suppresses PNPLA2-dependent lipolysis, leading to massive triglyceride accumulation in hepatocytes and brown adipocytes. Moreover, transgenic overexpression of PNPLA3 ${ }^{\mathrm{I} 158 \mathrm{M}}$ increases hepatic triglyceride levels in WT mice, but not in $A b h d 5^{-/-}$mice, confirming that the pro-steatotic effects of PNPLA3 require the presence of ABHD5. Thus, the increased abundance of PNPLA3 ${ }^{\mathrm{I} 148 \mathrm{M}}$ results in sequestration of ABHD5 on LDs, thereby limiting the availability of this cofactor for activation of PNPLA2. The question remains of how PNPLA2, PNPLA3, and ABHD5 each find their way to hepatocyte LDs in the correct stoichiometric proportions and function to regulate LD assembly and turnover under conditions of fasting or nutrient excess.

\subsection{PNPLA1 in Acylceramide Synthesis for Skin Barrier Function}

$\omega$-O-acylceramide, a unique sphingolipid present specifically in the stratum corneum of the epidermis, is essential for skin barrier formation, and impairment of its biosynthesis leads to ichthyosis or atopic dermatitis. Mutations in the human PNPLA1 gene cause autosomal recessive congenital ichthyosis [168]. Unlike most PNPLA isoforms that are ubiquitously expressed in many tissues, PNPLA1 is localized predominantly in the upper layer of the epidermis. PNPLA1 acts as a unique transacylase, catalyzing the transfer of LA in triglyceride to the $\omega$-hydroxy group of ultra-long-chain fatty acid in ceramide to give rise to $\omega$-O-acylceramide [169-171] (Figure 4B). Global or keratinocyte-specific deletion of PNPLA1 hampers epidermal $\omega$-O-acylceramide formation, thereby severely impairing skin barrier function leading to neonatal death due to excessive dehydration. The enzymatic activity of PNPLA1 is enhanced by ABHD5, which may present triglycerides to PNPLA1 to facilitate substrate recognition [172,173], providing a mechanism whereby ABHD5 mutations cause Chanarin-Dorfman syndrome accompanied by ichthyosis with impaired $\omega$-O-acylceramide formation. The role of PNPLA1 in $\omega$-O-acylceramide biosynthesis has been described in detail in a recent review [174].

\section{Other PLA2 Family}

\subsection{The PAF-AH Family}

The PAF-acetylhydrolase (PAF-AH) family comprises one extracellular and three intracellular enzymes that were originally found to have the capacity to deacetylate and thereby inactivate the lysophospholipid-derived lipid mediator PAF $[175,176]$. Plasma-type PAF-AH (group VIIA PLA 2 ; encoded by PLA2G7) is a secreted protein produced by macrophages, mast cells or other sources, and is now more generally referred to as lipoprotein-associated PLA (Lp-PLA $_{2}$ ), existing as a low-density lipoprotein (LDL)-bound form in human plasma [177]. Although PAF is a potent mediator of allergic responses, Lp-PLA 2 deficiency fails to augment airway inflammation or hyperresponsiveness after PAF+LPS treatment or passive or active allergic sensitization and challenge [178]. A series of clinical studies have revealed a correlation of Lp-PLA ${ }_{2}$ with atherosclerosis, likely because this enzyme hydrolyzes oxidized phospholipids (i.e., phospholipids having an oxidized fatty acid at the $s n-2$ position) in modified LDL with pro-atherogenic potential $[179,180]$. Although darapladib, a potent Lp-PLA 2 inhibitor, failed to meet the primary endpoints of two large phase III trials for treatment of atherosclerosis [181], recent clinical and preclinical studies have revealed that Lp-PLA 2 inhibition may have therapeutic effects in diabetic macular edema and Alzheimer's disease [182,183]. Lp-PLA 2 
deficiency in $A p c^{\mathrm{Min} /+}$ mice leads to decreased intestinal polyposis and tumorigenesis, suggesting a role of PAF or some oxidized lipids in cancer development [184].

Type-I PAF-AH is a heterotrimer composed of two catalytic $\alpha 1$ and $\alpha 2$ subunits (group XIIIA and XIIIB PLA ${ }_{2}$ s, encoded by PAFAH1B2 and PAFAH1B3, respectively), and a regulatory $\beta$ subunit that is identical to LIS-1, a causative gene for a type of Miller-Dieker syndrome [185]. Loss of both the $\alpha 1$ and $\alpha 2$ catalytic subunits leads to male infertility [186], reduction of amyloid- $\beta$ generation by promoting the degradation of amyloid precursor protein C-terminal fragments [187], and an increase in the size of the ganglionic eminences resulting from increased proliferation of GABAergic neurons through perturbation of the Wnt signaling pathway [188].

Type-II PAF-AH (PAF-AH2 or group VIIB PLA 2 ; encoded by PAFAH2) shows significant homology with Lp-PLA 2 and preferentially hydrolyzes oxidized phospholipids in cells. In a

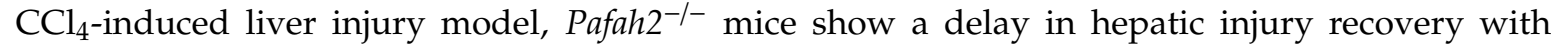
unusual accumulation of 8-isoprostaglandin $\mathrm{F}_{2 \alpha}\left(8\right.$-iso- $\left.\mathrm{PGF}_{2 \alpha}\right)$ in membrane phospholipids, indicating that PAF-AH2 removes toxic oxidized lipids from cell membranes and thereby protects the tissue from oxidative stress-induced injury [189]. Mast cells spontaneously produce $\omega 3$ PUFA-derived epoxides ( $\omega 3$ epoxides), such as EPA-derived 17,18-epoxyeicosatetraenoic acid (17,18-EpETE) and DHA-derived 19,20-epoxydocosapentaenoic acid (19,20-EpDPE), whose production depends on PAF-AH2-driven cleavage of $\omega 3$ epoxide-esterified phospholipids in mast cell membranes [190]. Genetic or pharmacological inactivation of PAF-AH2 reduces the steady-state production of $\omega 3$ epoxides, leading to attenuated mast cell activation and anaphylaxis following FceRI crosslinking (Figure 5). Mechanistically, the $\omega 3$ epoxides promote IgE-mediated activation of mast cells by down-regulating Srcin1, a Src-inhibitory protein that counteracts FceRI signaling, through a pathway involving PPAR $\gamma$. Thus, the PAF-AH2- $\omega 3$ epoxide pathway ensures optimal mast cell activation and presents new potential drug targets for allergic diseases. The properties and functions of the PAF-AH family have been summarized in a recent review [191].

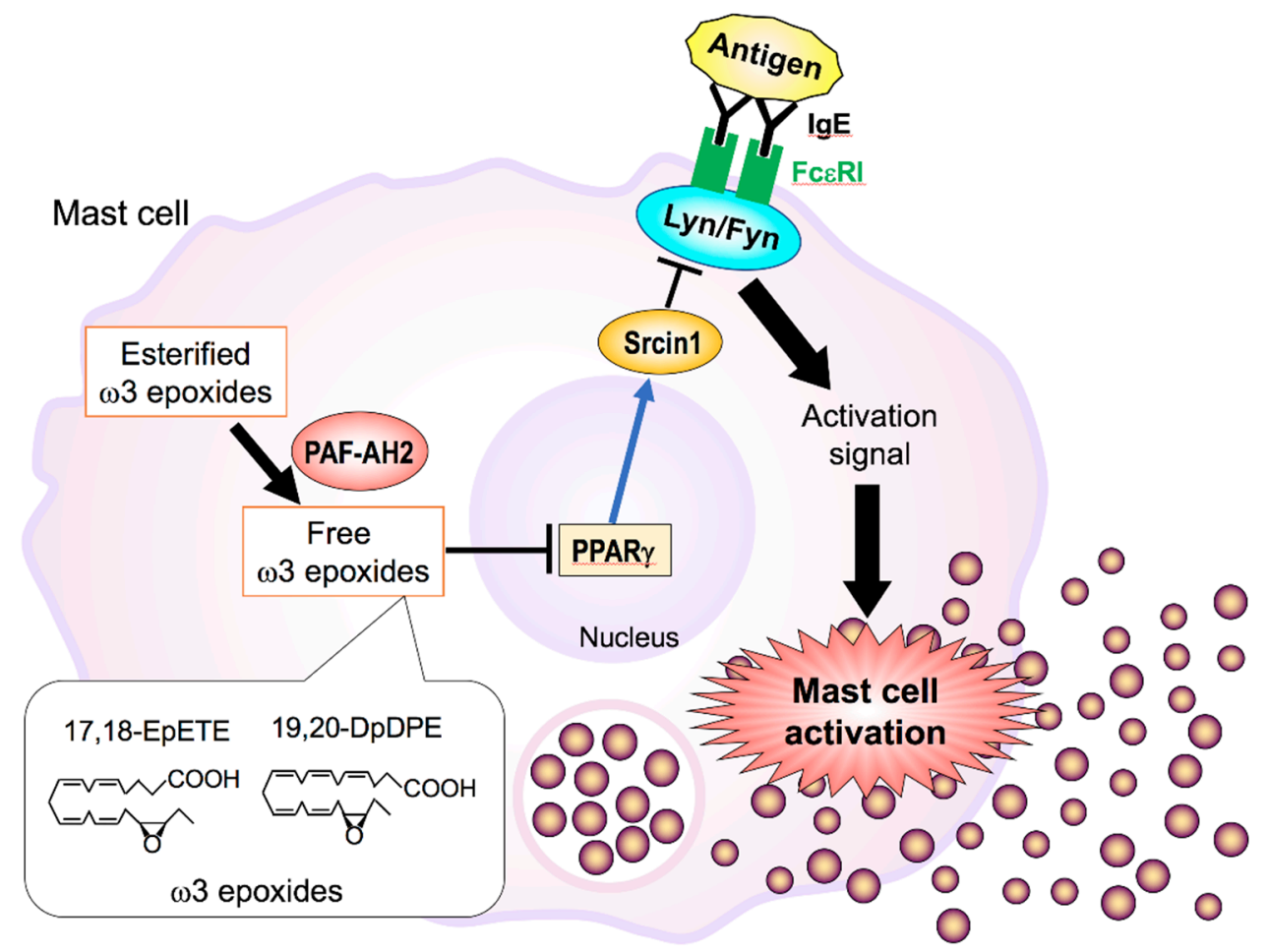

Figure 5. The role of PAF-AH2 in mast cell activation by producing $\omega 3$ epoxides. PAF-AH2 constitutively hydrolyzes $\omega 3$ epoxide-esterified phospholipids in cell membranes to liberate $\omega 3$ epoxides. These unique $\omega 3$ PUFA metabolites attenuate PPAR $\gamma$ signaling and downregulate Srcin1, which blocks activation of the Src family kinases Fyn and Lyn, thereby augmenting FcERI signaling. 


\subsection{Lysosomal PLA $A_{2}$}

Lysosomal PLA 2 (LPLA $_{2}$ or group XV PLA 2 ; encoded by PLA2G15) is catalytically active under mildly acidic conditions and structurally homologous with lecithin:cholesterol acyltransferase (LCAT), an enzyme that transfers the $s n-2$ fatty acid of PC to cholesterol to produce cholesteryl ester in high-density lipoprotein (HDL) [192]. LPLA 2 hydrolyzes both $s n-1$ and $s n-2$ fatty acids in phospholipids and contributes to phospholipid degradation in lysosomes. Genetic deletion of LPLA 2 results in unusual accumulation of non-degraded lung surfactant phospholipids in lysosomes of alveolar macrophages leading to phospholipidosis [193], reduced presentation of lysophospholipid antigens to CD1d by invariant natural killer T (iNKT) cells [194], and impairment of adaptive T cell immunity against mycobacterium [195].

Peroxiredoxin $6(\operatorname{Prdx} 6)$ is another lysosomal $\mathrm{PLA}_{2}$ that is also called acidic $\mathrm{Ca}^{2+}$-independent $\mathrm{PLA}_{2}\left(\right.$ aiPLA $\left.A_{2}\right)$ Prdx6 is a multifunctional enzyme since it also possesses glutathione peroxidase and lysophospholipid acyltransferase activities. The aiPLA $A_{2}$ activity of Prdx6 has important physiological roles in the turnover (synthesis and degradation) of lung surfactant phospholipids [196], protection against LPS-induced lung injury [197], repair of peroxidized cell membranes [198], and sperm fertilizing competence [199]. The properties and functions of LPLA 2 and Prdx6/aiPLA 2 have been summarized in recent reviews $[200,201]$.

\subsection{The PLAAT Family}

The PLAAT family, which comprises 3 enzymes in mice and 5 enzymes in humans, is structurally similar to lecithin:retinol acyltransferase (LRAT). Because of the ability of some members in this family to suppress $\mathrm{H}$-ras signaling, it is also referred to as the HRASLS (for $\mathrm{H}$-ras-like suppressor) family. Members of this family, including PLA2G16 (group XVI PLA 2 , also known as PLAAT3 or HRASLS3), display PLA $\mathrm{P}_{1}$ and $\mathrm{PLA}_{2}$ activities, as well as $\mathrm{Ca}^{2+}$-independent $\mathrm{N}$-acyltransferase activity that synthesizes NAPE, to various degrees [202]. PLA2G16 is highly expressed in adipocytes, and Pla2g $16^{-/-}$mice are resistant to diet-induced obesity [203]. Adipocyte-derived LPC produced by PLA2G16 activates NLRP3 inflammasomes in adipocytes and adipose tissue macrophages mediating homocysteine-induced insulin resistance [204]. PLA2G16 and its paralogs in this family have also been implicated in tumor invasion and metastasis [205], vitamin A metabolism [206], peroxisome biogenesis [207], and cellular entry and clearance of Picornaviruses [208]. The properties and functions of the PLAAT/PLA2G16 family have been summarized in recent reviews $[209,210]$.

\subsection{The ABHD Family}

The ABHD family is a newly recognized group of lipolytic enzymes, comprising at least 19 enzymes in humans [211]. Enzymes in this family typically possess both hydrolase and acyltransferase motifs. Although the functions of many of the ABHD isoforms still remain uncertain, some of them have been demonstrated to act on neutral lipids or phospholipids as lipid hydrolases. ABHD3 selectively hydrolyzes phospholipids with medium-chain fatty acids [212]. ABHD4 releases fatty acids from multiple classes of $N$-acyl-phospholipids to produce $N$-acyl-lysophospholipids [213]. ABHD6 acts as lysophospholipase or monoacylglycerol lipase, the latter being possibly related to signaling of 2-arachidonoyl glycerol, an endocannabinoid lipid mediator that plays a role in retrograde neurotransmission [214]. ABHD12 hydrolyzes lysophosphatidylserine (LysoPS), and is therefore referred to as LysoPS lipase [215]. Genetic or pharmacological blockade of ABHD12 stimulates immune responses in vivo, pointing to a key role for this enzyme in regulating immunostimulatory lipid pathways. Mutations in the human ABHD12 gene result in accumulation of LysoPS in the brain and cause a disease known as PHARC, which is characterized by polyneuropathy, hearing loss, ataxia, retinitis pigmentosa, and cataract [216]. ABHD16A acts as a PS-selective PLA 2 (referred to as PS lipase), lying upstream of ABHD12 in the PS-catabolic pathway [217]. Disruption of ABHD12 and ABHD16A in macrophages respectively increases and decreases LysoPS levels and cytokine production. Although 
ABHD5 does not have catalytic activity because of the absence of a serine residue in the catalytic center, it interacts with and modifies the functions of several PNPLA members including PNPLA1-3, as described above.

\subsection{GPI-Specific PLA $A_{2} \mathrm{~S}$}

GPI is a complex glycolipid covalently linked to the $C$ terminus of proteins on the plasma membrane, particularly in the raft microdomain. The biosynthesis of GPI and its attachment to proteins occur in the ER. GPI-anchoring proteins (GPI-APs) are subjected to fatty acid remodeling, which replaces an unsaturated fatty acid at the $s n-2$ position of the PI moiety with a saturated fatty acid. PGAP3, which resides in the Golgi, and PGAP6, which is localized mainly on the cell surface, are GPI-specific PLA $\mathrm{A}_{2} \mathrm{~s}$ (GPI-PLA ${ }_{2} \mathrm{~s}$ ) involved in fatty acid remodeling of GPI-APs [218]. PGAP3-dependent fatty acid remodeling of GPI-APs has a significant role in the control of autoimmunity, possibly by the regulation of apoptotic cell clearance and Th1/Th2 balance [219]. CRIPTO, a GPI-AP that plays critical roles in early embryonic development by acting as a Nodal co-receptor, is a highly sensitive substrate of PGAP6. CRIPTO is released by PGAP6 as a glycosyllysophosphatidylinositol-bound form and acts as a co-receptor in Nodal signaling. Pgap $6^{-/-}$mice show defects in early embryonic development, particularly in the formation of the anterior-posterior axis, as do Cripto ${ }^{-/}$embryos, suggesting that PGAP6 plays a critical role in Nodal signaling modulation through CRIPTO shedding [220].

\section{Conclusions}

In this review, we have provided an overview of the biological functions of a nearly full set of $\mathrm{PLA}_{2} \mathrm{~S}$ identified to date, particularly over the past five years during which considerable advances in this research field have been made. In the interests of brevity, we have referenced previous reviews whenever possible and apologize to the authors of the numerous original papers that were not explicitly cited. By applying lipidomics approaches to knockout or transgenic mice for various $\mathrm{PLA}_{2} \mathrm{~s}$, it has become evident that individual enzymes regulate specific forms of lipid metabolism, perturbation of which can be eventually linked to distinct pathophysiological outcomes. Knowledge of individual $\mathrm{PLA}_{2} \mathrm{~S}$ acquired from studies using animal models is now being translated to humans. Note that the designation "PLA ${ }_{2}$ " is used more broadly for enzymes that have significant homology with prototypic PLA 2 subtypes, even if they do not necessarily exert PLA 2 activity. These examples include, for instance, $\mathrm{N}$-acyltransferase $\left(\mathrm{cPLA}_{2} \varepsilon\right), \omega$-O-acylceramide synthase (PNPLA1), triglyceride lipase (PNPLA2 and PNPLA3), and lysophospholipase (PNPLA6 and PNPLA7). Several PLA 2 s, such as ${ }_{c} P L A_{2} \delta, \mathrm{PLA}_{2} \gamma$, and PLA2G16, possess PLA ${ }_{1}$ activity that is even superior to $\mathrm{PLA}_{2}$ activity, although biological importance of the $s n-1$ cleavage by these $\mathrm{PLA}_{2} \mathrm{~S}$ is largely unclear. There are also several enzymes that possess PLA ${ }_{2}$ activity but are not designated as $\mathrm{PLA}_{2}$, as exemplified by the ABHD and GPI-specific PLA 2 families. Thus, the term "PLA ${ }_{2}$ " is somehow confusing and should be interpreted with caution if researchers encounter the genetic symbol "PLA2" on genome-wide transcriptome and proteome analyses.

Lipid metabolic pathways are complex, often redundant and highly interconnected, in some cases being counter regulatory. As recently reviewed by Kokotos and coworkers [221], various PLA 2 subtypes are being targeted pharmacologically to alleviate the symptoms of various disease models, but none of the $\mathrm{PLA}_{2}$ inhibitors currently developed has reached the market yet. If the modulation of one PLA 2 pathway does not suffice therapeutically, targeting two or more pathways could be effective. On the other hand, blunting of related PLA 2 subtypes simultaneously may not be therapeutically efficient in some cases, since this strategy would block both positive and negative pathways regulated by distinct isoforms. For instance, pan-sPLA ${ }_{2}$ inhibitors (e.g., varespladib), which inhibit group I/II/V/X $\mathrm{sPLA}_{2} \mathrm{~s}$ altogether, have been reported to exert a poor therapeutic effect on atherosclerosis, arthritis, and allergy, probably because they blunt both offensive and defensive $\mathrm{SLA}_{2} \mathrm{~s}$. This points to potential prophylactic or therapeutic use of an agent that could specifically inhibit a particular PLA $_{2}$ subtype, 
even though such a strategy will be a challenge since individual $\mathrm{PLA}_{2} \mathrm{~S}$ appear to play highly selective and often opposite roles in specific organs and disease states.

At present, the tools that are available for following the dynamics of individual $\mathrm{PLA}_{2} \mathrm{~S}$ and associated lipid metabolites and for monitoring their precise modifications and spatiotemporal localizations are still technically limited. The actions of lipids are frequently masked by the large steady-state mass of structural lipids in membranes, making it difficult to detect spatiotemporal lipid dynamics and functions. Further advances in this field and their integration for therapeutic use are likely to benefit from improved, time- and space-resolved lipidomics technology for monitoring individual $\mathrm{PLA}_{2} \mathrm{~s}$ and associated lipid metabolisms within tissue microenvironments. It seems that more work will be necessary to dissect each of the many regulated pathways of bioactive lipids and to define the mechanisms responsible for the regulatory actions of individual $\mathrm{PLA}_{2} \mathrm{~s}$, as well as the roles of the pathways in specific responses at the cell, tissue, and organism level. Hopefully, the next decade will yield a more integrated view of the overall map of the PLA 2 network in biology, allowing the therapeutic application of inhibitors or the lipid products of some enzymes to human diseases.

Author Contributions: M.M. wrote the manuscript. Figures were prepared by H.S. and Y.T. All authors have read and agreed to the published version of the manuscript.

Funding: This work was supported by Grants-in-Aid for Scientific Research JP16H02613 and JP20H05691 from Japan Society for the Promotion of Science and AMED-CREST 20gm1210013 and FORCE 19gm4010005from the Japan Agency for Medical Research and Development (to M.M.).

Acknowledgments: We thank all past and present members of the PLA 2 group for their contributions to the scientific work emanating from our laboratory. This article summarizes work from a large number of published papers; however, due to space limitations we have been unable to include all relevant publications in our discussion. We apologize to those authors whose relevant work has not been included in this review article.

Conflicts of Interest: The authors declare no conflict of interest.

\section{References}

1. Murakami, M. Novel functions of phospholipase $\mathrm{A}_{2}$ s: Overview. Biochim. Biophys. Acta Mol. Cell Biol. Lipids 2019, 1864, 763-765. [CrossRef] [PubMed]

2. Murakami, M.; Taketomi, Y.; Miki, Y.; Sato, H.; Hirabayashi, T.; Yamamoto, K. Recent progress in phospholipase $\mathrm{A}_{2}$ research: From cells to animals to humans. Prog. Lipid Res. 2011, 50, 152-192. [CrossRef] [PubMed]

3. Murakami, M. Lipoquality control by phospholipase $\mathrm{A}_{2}$ enzymes. Proc. Jpn. Acad. Ser. B 2017, 93, 677-702. [CrossRef] [PubMed]

4. Murakami, M.; Taketomi, Y.; Girard, C.; Yamamoto, K.; Lambeau, G. Emerging roles of secreted phospholipase $\mathrm{A}_{2}$ enzymes: Lessons from transgenic and knockout mice. Biochimie 2010, 92, 561-582. [CrossRef]

5. Murakami, M.; Taketomi, Y.; Sato, H.; Yamamoto, K. Secreted phospholipase $A_{2}$ revisited. J. Biochem. 2011, 150, 233-255. [CrossRef] [PubMed]

6. Murakami, M.; Sato, H.; Miki, Y.; Yamamoto, K.; Taketomi, Y. A new era of secreted phospholipase A 2 . J. Lipid Res. 2015, 56, 1248-1261. [CrossRef]

7. Murakami, M.; Yamamoto, K.; Miki, Y.; Murase, R.; Sato, H.; Taketomi, Y. The roles of the secreted phospholipase $\mathrm{A}_{2}$ gene family in immunology. Adv. Immunol. 2016, 132, 91-134. [CrossRef]

8. Lambeau, G.; Gelb, M.H. Biochemistry and physiology of mammalian secreted phospholipases $\mathrm{A}_{2}$. Annu. Rev. Biochem. 2008, 77, 495-520. [CrossRef]

9. Murakami, M.; Miki, Y.; Sato, H.; Murase, R.; Taketomi, Y.; Yamamoto, K. Group IID, IIE, IIF and III secreted phospholipase $\mathrm{A}_{2}$ s. Biochim. Biophys. Acta Mol. Cell Biol. Lipids 2019, 1864, 803-818. [CrossRef]

10. Seilhamer, J.J.; Randall, T.L.; Yamanaka, M.; Johnson, L.K. Pancreatic phospholipase $\mathrm{A}_{2}$ : Isolation of the human gene and cDNAs from porcine pancreas and human lung. DNA 1986, 5, 519-527. [CrossRef]

11. Hollie, N.I.; Konaniah, E.S.; Goodin, C.; Hui, D.Y. Group 1B phospholipase $\mathrm{A}_{2}$ inactivation suppresses atherosclerosis and metabolic diseases in LDL receptor-deficient mice. Atherosclerosis. 2014, 234, 377-380. [CrossRef] [PubMed] 
12. Huggins, K.W.; Boileau, A.C.; Hui, D.Y. Protection against diet-induced obesity and obesity- related insulin resistance in group 1B PLA 2 -deficient mice. Am. J. Physiol. Metab. 2002, 283, E994-E1001. [CrossRef] [PubMed]

13. Hui, D.Y.; Cope, M.J.; Labonté, E.D.; Chang, H.-T.; Shao, J.; Goka, E.; Abousalham, A.; Charmot, D.; Buysse, J. The phospholipase $A_{2}$ inhibitor methyl indoxam suppresses diet-induced obesity and glucose intolerance in mice. Br. J. Pharmacol. 2009, 157, 1263-1269. [CrossRef] [PubMed]

14. Labonté, E.D.; Kirby, R.J.; Schildmeyer, N.M.; Cannon, A.M.; Huggins, K.W.; Hui, D.Y. Phospholipase $\mathrm{A}_{2}$-mediated lysophospholipid absorption directly contributes to postprandial hyperglycemia. Diabetes 2006, 55, 935-941. [CrossRef]

15. Wilson, S.G.; Adam, G.; Langdown, M.; Reneland, R.; Braun, A.; Andrew, T.; Surdulescu, G.L.; Norberg, M.; Dudbridge, F.; Reed, P.W.; et al. Linkage and potential association of obesity-related phenotypes with two genes on chromosome 12q24 in a female dizygous twin cohort. Eur. J. Hum. Genet. 2006, 14, 340-348. [CrossRef]

16. Hui, D.Y. Group $1 \mathrm{~B}$ phospholipase $\mathrm{A}_{2}$ in metabolic and inflammatory disease modulation. Biochim. Biophys. Acta Mol. Cell Biol. Lipids 2019, 1864, 784-788. [CrossRef]

17. Entwistle, L.J.; Pelly, V.S.; Coomes, S.M.; Kannan, Y.; Perez-Lloret, J.; Czieso, S.; Dos Santos, M.S.; Macrae, J.I.; Collinson, L.M.; Sesay, A.; et al. Epithelial-cell-derived phospholipase $\mathrm{A}_{2}$ group $1 \mathrm{~B}$ is an endogenous anthelmintic. Cell Host Microbe 2017, 22, 484-493.e5. [CrossRef]

18. Pothlichet, J.; Rose, T.; Bugault, F.; Jeammet, L.; Meola, A.; Haouz, A.; Saul, F.; Geny, D.; Alcami, J.; Ruiz-Mateos, E.; et al. PLA2G1B is involved in CD4 anergy and CD4 lymphopenia in HIV-infected patients. J. Clin. Investig. 2020, 130, 2872-2887. [CrossRef]

19. Laine, V.J.; Grass, D.S.; Nevalainen, T.J. Protection by group II phospholipase $\mathrm{A}_{2}$ against Staphylococcus aureus. J. Immunol. 1999, 162, 7402-7408.

20. Weinrauch, Y.; Abad, C.; Liang, N.S.; Lowry, S.F.; Weiss, J. Mobilization of potent plasma bactericidal activity during systemic bacterial challenge. Role of group IIA phospholipase A2. J. Clin. Investig. 1998, 102, 633-638. [CrossRef]

21. Pernet, E.; Guillemot, L.; Burgel, P.-R.; Martin, C.; Lambeau, G.; Sermet-Gaudelus, I.; Sands, D.; LeDuc, D.; Morand, P.C.; Jeammet, L.; et al. Pseudomonas aeruginosa eradicates Staphylococcus aureus by manipulating the host immunity. Nat. Commun. 2014, 5, 5105. [CrossRef]

22. Hamaguchi, K.; Kuwata, H.; Yoshihara, K.; Masuda, S.; Shimbara, S.; Oh-Ishi, S.; Murakami, M.; Kudo, I. Induction of distinct sets of secretory phospholipase $\mathrm{A}_{2}$ in rodents during inflammation. Biochim. Biophys. Acta Bioenerg. 2003, 1635, 37-47. [CrossRef] [PubMed]

23. Boudreau, L.H.; Duchez, A.-C.; Cloutier, N.; Soulet, D.; Martin, N.; Bollinger, J.; Paré, A.; Rousseau, M.; Naika, G.S.; Lévesque, T.; et al. Platelets release mitochondria serving as substrate for bactericidal group IIA-secreted phospholipase $\mathrm{A}_{2}$ to promote inflammation. Blood 2014, 124, 2173-2183. [CrossRef] [PubMed]

24. Duchez, A.-C.; Boudreau, L.H.; Naika, G.S.; Bollinger, J.; Belleannée, C.; Cloutier, N.; Laffont, B.; Mendoza-Villarroel, R.E.; Lévesque, T.; Rollet-Labelle, E.; et al. Platelet microparticles are internalized in neutrophils via the concerted activity of 12-lipoxygenase and secreted phospholipase $\mathrm{A}_{2}$-IIA. Proc. Natl. Acad. Sci. USA 2015, 112, E3564-E3573. [CrossRef]

25. Dore, E.; Boilard, E. Roles of secreted phospholipase $\mathrm{A}_{2}$ group IIA in inflammation and host defense. Biochim. Biophys. Acta Mol. Cell Biol. Lipids 2019, 1864, 789-802. [CrossRef] [PubMed]

26. Dacheux, M.; Sinou, V.; Payré, C.; Jeammet, L.; Parzy, D.; Grellier, P.; Deregnaucourt, C.; Lambeau, G. Antimalarial activity of human group IIA secreted phospholipase $\mathrm{A}_{2}$ in relation to enzymatic hydrolysis of oxidized lipoproteins. Infect. Immun. 2019, 87, e00556-19. [CrossRef] [PubMed]

27. Grass, D.S.; Felkner, R.H.; Chiang, M.Y.; Wallace, R.E.; Nevalainen, T.J.; Bennett, C.F.; Swanson, M.E. Expression of human group II PLA 2 in transgenic mice results in epidermal hyperplasia in the absence of inflammatory infiltrate. J. Clin. Investig. 1996, 97, 2233-2241. [CrossRef]

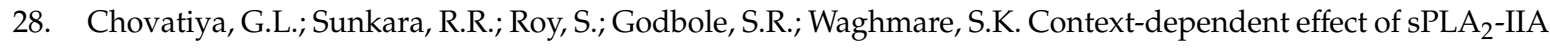
induced proliferation on murine hair follicle stem cells and human epithelial cancer. EBioMedicine 2019, 48, 364-376. [CrossRef] [PubMed]

29. Kuefner, M.S.; Deng, X.; Stephenson, E.J.; Pham, K.; Park, E.A. Secretory phospholipase $A_{2}$ group IIA enhances the metabolic rate and increases glucose utilization in response to thyroid hormone. FASEB J. 2018, 33, 738-749. [CrossRef] 
30. Macphee, M.; Chepenik, K.P.; Liddell, R.A.; Nelson, K.K.; Siracusa, L.D.; Buchberg, A.M. The secretory phospholipase $\mathrm{A}_{2}$ gene is a candidate for the Mom1 locus, a major modifier of $A p c^{M i n}$-induced intestinal neoplasia. Cell 1995, 81, 957-966. [CrossRef]

31. Yamamoto, K.; Miki, Y.; Sato, M.; Taketomi, Y.; Nishito, Y.; Taya, C.; Muramatsu, K.; Ikeda, K.; Nakanishi, H.; Taguchi, R.; et al. The role of group IIF-secreted phospholipase $\mathrm{A}_{2}$ in epidermal homeostasis and hyperplasia. J. Exp. Med. 2015, 212, 1901-1919. [CrossRef] [PubMed]

32. Schewe, M.; Franken, P.F.; Sacchetti, A.; Schmitt, M.; Joosten, R.; Böttcher, R.; Van Royen, M.E.; Jeammet, L.; Payre, C.; Scott, P.M.; et al. Secreted phospholipases $\mathrm{A}_{2}$ are intestinal stem cell niche factors with distinct roles in homeostasis, inflammation, and cancer. Cell Stem Cell 2016, 19, 38-51. [CrossRef] [PubMed]

33. Murase, R.; Sato, H.; Yamamoto, K.; Ushida, A.; Nishito, Y.; Ikeda, K.; Kobayashi, T.; Yamamoto, T.; Taketomi, Y.; Murakami, M. Group X secreted phospholipase $\mathrm{A}_{2}$ releases $\omega 3$ polyunsaturated fatty acids, suppresses colitis, and promotes sperm fertility. J. Biol. Chem. 2016, 291, 6895-6911. [CrossRef] [PubMed]

34. Rouault, M.; Le Calvez, C.; Boilard, E.; Surrel, F.; Singer, A.; Ghomashchi, F.; Bezzine, S.; Scarzello, S.; Bollinger, J.; Gelb, M.H.; et al. Recombinant production and properties of binding of the full set of mouse secreted phospholipases $A_{2}$ to the mouse M-type receptor. Biochemistry 2007, 46, 1647-1662. [CrossRef]

35. Kishi, H.; Yamaguchi, K.; Watanabe, K.; Nakamura, K.; Fujioka, D.; Kugiyama, K. Deficiency of phospholipase $\mathrm{A}_{2}$ receptor exacerbates autoimmune myocarditis in mice. Inflammation 2020, 43, 1097-1109. [CrossRef]

36. Miki, Y.; Yamamoto, K.; Taketomi, Y.; Sato, H.; Shimo, K.; Kobayashi, T.; Ishikawa, Y.; Ishii, T.; Nakanishi, H.; Ikeda, K.; et al. Lymphoid tissue phospholipase $\mathrm{A}_{2}$ group IID resolves contact hypersensitivity by driving antiinflammatory lipid mediators. J. Exp. Med. 2013, 210, 1217-1234. [CrossRef]

37. Miki, Y.; Kidoguchi, Y.; Sato, M.; Taketomi, Y.; Taya, C.; Muramatsu, K.; Gelb, M.H.; Yamamoto, K.; Murakami, M. Dual roles of group IID phospholipase $\mathrm{A}_{2}$ in inflammation and cancer. J. Biol. Chem. 2016, 291, 15588-15601. [CrossRef]

38. Vijay, R.; Hua, X.; Meyerholz, D.K.; Miki, Y.; Yamamoto, K.; Gelb, M.; Murakami, M.; Perlman, S. Critical role of phospholipase $\mathrm{A}_{2}$ group IID in age-related susceptibility to severe acute respiratory syndrome-CoV infection. J. Exp. Med. 2015, 212, 1851-1868. [CrossRef]

39. Sato, H.; Taketomi, Y.; Miki, Y.; Murase, R.; Yamamoto, K.; Murakami, M. Secreted phospholipase PLA2G2D contributes to metabolic health by mobilizing $\omega 3$ polyunsaturated fatty acids in WAT. Cell Rep. 2020, 31, 107579. [CrossRef]

40. Takabatake, N.; Sata, M.; Inoue, S.; Shibata, Y.; Abe, S.; Wada, T.; Machiya, J.-I.; Ji, G.; Matsuura, T.; Takeishi, Y.; et al. A novel polymorphism in secretory phospholipase $\mathrm{A}_{2}$-IID is associated with body weight loss in chronic obstructive pulmonary disease. Am. J. Respir. Crit. Care Med. 2005, 172, 1097-1104. [CrossRef]

41. Sato, H.; Taketomi, Y.; Ushida, A.; Isogai, Y.; Kojima, T.; Hirabayashi, T.; Miki, Y.; Yamamoto, K.; Nishito, Y.; Kobayashi, T.; et al. The adipocyte-inducible secreted phospholipases PLA2G5 and PLA2G2E play distinct roles in obesity. Cell Metab. 2014, 20, 119-132. [CrossRef] [PubMed]

42. Yamamoto, K.; Miki, Y.; Sato, H.; Nishito, Y.; Gelb, M.H.; Taketomi, Y.; Murakami, M. Expression and function of group IIE phospholipase $\mathrm{A}_{2}$ in mouse skin. J. Biol. Chem. 2016, 291, 15602-15613. [CrossRef]

43. Valentin, E. Novel secreted phospholipase $\mathrm{A}_{2}$ with homology to the group III bee venom enzyme. J. Biol. Chem. 2000, 275, 7492-7496. [CrossRef]

44. Murakami, M.; Masuda, S.; Shimbara, S.; Bezzine, S.; Lazdunski, M.; Lambeau, G.; Gelb, M.H.; Matsukura, S.; Kokubu, F.; Adachi, M.; et al. Cellular arachidonate-releasing function of novel classes of secretory phospholipase $\mathrm{A}_{2} \mathrm{~s}$ (groups III and XII). J. Biol. Chem. 2003, 278, 10657-10667. [CrossRef]

45. Sato, H.; Taketomi, Y.; Isogai, Y.; Miki, Y.; Yamamoto, K.; Masuda, S.; Hosono, T.; Arata, S.; Ishikawa, Y.; Ishii, T; et al. Group III secreted phospholipase $\mathrm{A}_{2}$ regulates epididymal sperm maturation and fertility in mice. J. Clin. Investig. 2010, 120, 1400-1414. [CrossRef] [PubMed]

46. Taketomi, Y.; Ueno, N.; Kojima, T.; Sato, H.; Murase, R.; Yamamoto, K.; Tanaka, S.; Sakanaka, M.; Nakamura, M.; Nishito, Y.; et al. Mast cell maturation is driven via a group III phospholipase $\mathrm{A}_{2}$-prostaglandin $\mathrm{D}_{2}$-DP1 receptor paracrine axis. Nat. Immunol. 2013, 14, 554-563. [CrossRef]

47. Murakami, M.; Masuda, S.; Shimbara, S.; Ishikawa, Y.; Ishii, T.; Kudo, I. Cellular distribution, post-translational modification, and tumorigenic potential of human group III secreted phospholipase $\mathrm{A}_{2}$. J. Biol. Chem. 2005, 280, 24987-24998. [CrossRef] [PubMed] 
48. Kazama, S.; Kitayama, J.; Hiyoshi, M.; Taketomi, Y.; Murakami, M.; Nishikawa, T.; Tanaka, T.; Tanaka, J.; Kiyomatsu, T.; Kawai, K.; et al. Phospholipase $\mathrm{A}_{2}$ group III and group X have opposing associations with prognosis in colorectal cancer. Anticancer Res. 2015, 35, 2983-2990. [PubMed]

49. Hoeft, B.; Linseisen, J.; Beckmann, L.; Müller-Decker, K.; Canzian, F.; Hüsing, A.; Kaaks, R.; Vogel, U.; Jakobsen, M.U.; Overvad, K.; et al. Polymorphisms in fatty acid metabolism-related genes are associated with colorectal cancer risk. Carcinog. 2009, 31, 466-472. [CrossRef]

50. Murase, R.; Taketomi, Y.; Miki, Y.; Nishito, Y.; Saito, M.; Fukami, K.; Yamamoto, K.; Murakami, M. Group III phospholipase $\mathrm{A}_{2}$ promotes colitis and colorectal cancer. Sci. Rep. 2017, 7, 12261. [CrossRef] [PubMed]

51. Lin, S.; Wang, D.; Iyer, S.; Ghaleb, A.M.; Shim, H.; Yang, V.W.; Chun, J.; Yun, C.C. The absence of LPA 2 attenuates tumor formation in an experimental model of colitis-associated cancer. Gastroenterol. 2009, 136, 1711-1720. [CrossRef] [PubMed]

52. Stančić, A.; Jandl, K.; Hasenöhrl, C.; Reichmann, F.; Marsche, G.; Schuligoi, R.; Heinemann, A.; Storr, M.A.; Schicho, R. The GPR55 antagonist CID16020046 protects against intestinal inflammation. Neurogastroenterol. Motil. 2015, 27, 1432-1445. [CrossRef] [PubMed]

53. Murakami, M.; Koduri, R.S.; Enomoto, A.; Shimbara, S.; Seki, M.; Yoshihara, K.; Singer, A.; Valentin, E.; Ghomashchi, F.; Lambeau, G.; et al. Distinct arachidonate-releasing functions of mammalian secreted phospholipase $\mathrm{A}_{2} \mathrm{~S}$ in human embryonic kidney 293 and rat mastocytoma RBL-2H3 cells through heparan sulfate shuttling and external plasma membrane mechanisms. J. Biol. Chem. 2000, 276, 10083-10096. [CrossRef] [PubMed]

54. Murakami, M.; Shimbara, S.; Kambe, T.; Kuwata, H.; Winstead, M.V.; Tischfield, J.A.; Kudo, I. The functions of five distinct mammalian phospholipase $\mathrm{A}_{2} \mathrm{~S}$ in regulating arachidonic acid release. Type IIa and type $\mathrm{V}$ secretory phospholipase $\mathrm{A}_{2} \mathrm{~s}$ are functionally redundant and act in concert with cytosolic phospholipase $\mathrm{A}_{2}$. J. Biol. Chem. 1998, 273, 14411-14423. [CrossRef]

55. Ohtsuki, M.; Taketomi, Y.; Arata, S.; Masuda, S.; Ishikawa, Y.; Ishii, T.; Takanezawa, Y.; Aoki, J.; Arai, H.; Yamamoto, K.; et al. Transgenic expression of group V, but not group $\mathrm{X}$, secreted phospholipase $\mathrm{A}_{2}$ in mice leads to neonatal lethality because of lung dysfunction. J. Biol. Chem. 2006, 281, 36420-36433. [CrossRef]

56. Wootton, P.T.; Arora, N.L.; Drenos, F.; Thompson, S.R.; Cooper, J.A.; Stephens, J.W.; Hurel, S.J.; Hurt-Camejo, E.; Wiklund, O.; Humphries, S.E.; et al. Tagging SNP haplotype analysis of the secretory PLA $2-\mathrm{V}$ gene, PLA2G5, shows strong association with LDL and oxLDL levels, suggesting functional distinction from sPLA -IIA: $^{2}$ Results from the UDACS study. Hum. Mol. Genet. 2007, 16, 1437-1444. [CrossRef]

57. Ohta, S.; Imamura, M.; Xing, W.; Boyce, J.A.; Balestrieri, B. Group V secretory phospholipase $\mathrm{A}_{2}$ is involved in macrophage activation and is sufficient for macrophage effector functions in allergic pulmonary inflammation. J. Immunol. 2013, 190, 5927-5938. [CrossRef]

58. Yamaguchi, M.; Samuchiwal, S.K.; Quehenberger, O.; Boyce, J.A.; Balestrieri, B. Macrophages regulate lung ILC2 activation via Pla2g5-dependent mechanisms. Mucosal Immunol. 2017, 11, 615-626. [CrossRef]

59. Samuchiwal, S.K.; Balestrieri, B. Harmful and protective roles of group V phospholipase $\mathrm{A}_{2}$ : Current perspectives and future directions. Biochim. Biophys. Acta Mol. Cell Biol. Lipids 2019, 1864, 819-826. [CrossRef]

60. Balestrieri, B.; Maekawa, A.; Xing, W.; Gelb, M.H.; Katz, H.R.; Arm, J.P. Group V secretory phospholipase A $_{2}$ modulates phagosome maturation and regulates the innate immune response against Candida albicans. J. Immunol. 2009, 182, 4891-4898. [CrossRef]

61. Boilard, E.; Lai, Y.; Larabee, K.; Balestrieri, B.; Ghomashchi, F.; Fujioka, D.; Gobezie, R.; Coblyn, J.S.; Weinblatt, M.E.; Massarotti, E.M.; et al. A novel anti-inflammatory role for secretory phospholipase $\mathrm{A}_{2}$ in immune complex-mediated arthritis. EMBO Mol. Med. 2010, 2, 172-187. [CrossRef]

62. Degousee, N.; Kelvin, D.J.; Geisslinger, G.; Hwang, D.M.; Stefanski, E.; Wang, X.-H.; Danesh, A.; Angioni, C.; Schmidt, H.; Lindsay, T.F.; et al. Group V phospholipase $A_{2}$ in bone marrow-derived myeloid cells and bronchial epithelial cells promotes bacterial clearance after Escherichia coli pneumonia. J. Biol. Chem. 2011, 286, 35650-35662. [CrossRef] [PubMed]

63. Rubio, J.M.; Rodríguez, J.P.; Gil-De-Gómez, L.; Guijas, C.; Balboa, M.A.; Balsinde, J. Group V secreted phospholipase $\mathrm{A}_{2}$ is upregulated by IL-4 in human macrophages and mediates phagocytosis via hydrolysis of ethanolamine phospholipids. J. Immunol. 2015, 194, 3327-3339. [CrossRef]

64. Nienaber, C.A.; Clough, R.E.; Sakalihasan, N.; Suzuki, T.; Gibbs, R.; Mussa, F.; Jenkins, M.P.; Thompson, M.M.; Evangelista, A.; Yeh, J.S.M.; et al. Aortic dissection. Nat. Rev. Dis. Prim. 2016, 2, 16054. [CrossRef] [PubMed] 
65. Watanabe, K.; Taketomi, Y.; Miki, Y.; Kugiyama, K.; Murakami, M. Group V secreted phospholipase $A_{2}$ plays a protective role against aortic dissection. J. Biol. Chem. 2020, 295, 10092-10111. [CrossRef] [PubMed]

66. Jemel, I.; Ii, H.; Oslund, R.C.; Payré, C.; Dabert-Gay, A.-S.; Douguet, D.; Chargui, K.; Scarzello, S.; Gelb, M.H.; Lambeau, G. Group X secreted phospholipase $\mathrm{A}_{2}$ proenzyme is matured by a furin-like proprotein convertase and releases arachidonic acid inside of human HEK293 cells. J. Biol. Chem. 2011, 286, 36509-36521. [CrossRef]

67. Escoffier, J.; Jemel, I.; Tanemoto, A.; Taketomi, Y.; Payré, C.; Coatrieux, C.; Sato, H.; Yamamoto, K.; Masuda, S.; Pernet-Gallay, K.; et al. Group X phospholipase $\mathrm{A}_{2}$ is released during sperm acrosome reaction and controls fertility outcome in mice. J. Clin. Investig. 2010, 120, 1415-1428. [CrossRef] [PubMed]

68. Nahed, R.A.; Martinez, G.; Escoffier, J.; Yassine, S.; Karaouzene, T.; Hograindleur, J.-P.; Turk, J.; Kokotos, G.; Ray, P.F.; Bottari, S.P.; et al. Progesterone-induced acrosome exocytosis requires sequential involvement of calcium-independent phospholipase $\mathrm{A}_{2} \beta\left(\mathrm{iPLA}_{2} \beta\right)$ and group X secreted phospholipase $\mathrm{A}_{2}\left(\mathrm{sLA}_{2}\right)$. J. Biol. Chem. 2015, 291, 3076-3089. [CrossRef] [PubMed]

69. Sato, H.; Isogai, Y.; Masuda, S.; Taketomi, Y.; Miki, Y.; Kamei, D.; Hara, S.; Kobayashi, T.; Ishikawa, Y.; Ishii, T.; et al. Physiological roles of group $\mathrm{X}$-secreted phospholipase $\mathrm{A}_{2}$ in reproduction, gastrointestinal phospholipid digestion, and neuronal function. J. Biol. Chem. 2011, 286, 11632-11648. [CrossRef]

70. Ait-Oufella, H.; Herbin, O.; Lahoute, C.; Coatrieux, C.; Loyer, X.; Joffre, J.; Laurans, L.; Ramkhelawon, B.; Blanc-Brude, O.; Karabina, S.; et al. Group X secreted phospholipase $\mathrm{A}_{2}$ limits the development of atherosclerosis in LDL receptor-null mice. Arter. Thromb. Vasc. Biol. 2013, 33, 466-473. [CrossRef]

71. Li, X.; Shridas, P.; Forrest, K.; Bailey, W.; Webb, N.R. Group X secretory phospholipase $\mathrm{A}_{2}$ negatively regulates adipogenesis in murine models. FASEB J. 2010, 24, 4313-4324. [CrossRef]

72. Zack, M.; Boyanovsky, B.B.; Shridas, P.; Bailey, W.; Forrest, K.; Howatt, D.A.; Gelb, M.H.; De Beer, F.C.; Daugherty, A.; Webb, N.R. Group X secretory phospholipase $\mathrm{A}_{2}$ augments angiotensin II-induced inflammatory responses and abdominal aortic aneurysm formation in apoE-deficient mice. Atheroscler. 2011, 214, 58-64. [CrossRef] [PubMed]

73. Henderson, W.R.; Chi, E.Y.; Bollinger, J.G.; Tien, Y.-T.; Ye, X.; Castelli, L.; Rubtsov, Y.; Singer, A.G.; Chiang, G.K.; Nevalainen, T.; et al. Importance of group $\mathrm{X}$-secreted phospholipase $\mathrm{A}_{2}$ in allergen-induced airway inflammation and remodeling in a mouse asthma model. J. Exp. Med. 2007, 204, 865-877. [CrossRef]

74. Nolin, J.D.; Lai, Y.; Ogden, H.L.; Manicone, A.M.; Murphy, R.C.; An, D.; Frevert, C.W.; Ghomashchi, F.; Naika, G.S.; Gelb, M.H.; et al. Secreted PLA 2 group X orchestrates innate and adaptive immune responses to inhaled allergen. JCI Insight 2017, 2, e94929. [CrossRef] [PubMed]

75. Ogden, H.L.; Lai, Y.; Nolin, J.D.; An, D.; Frevert, C.W.; Gelb, M.H.; Altemeier, W.A.; Hallstrand, T.S. Secreted phospholipase $\mathrm{A}_{2}$ group $\mathrm{X}$ acts as an adjuvant for type 2 inflammation, leading to an allergen-specific immune response in the lung. J. Immunol. 2020, 204, 3097-3107. [CrossRef]

76. Nolin, J.D.; Murphy, R.C.; Gelb, M.H.; Altemeier, W.A.; Henderson, W.R.; Hallstrand, T.S. Function of secreted phospholipase $\mathrm{A}_{2}$ group-X in asthma and allergic disease. Biochim. Biophys. Acta Mol. Cell Biol. Lipids 2019, 1864, 827-837. [CrossRef] [PubMed]

77. Ohto, T.; Uozumi, N.; Hirabayashi, T.; Shimizu, T. Identification of novel cytosolic phospholipase $\mathrm{A}_{2} \mathrm{~s}$, murine ${ }_{c P L A} \delta, \epsilon$, and $\zeta$, which form a gene cluster with $\mathrm{cPLA}_{2} \beta$. J. Biol. Chem. 2005, 280, 24576-24583. [CrossRef]

78. Ghosh, M.; Loper, R.; Gelb, M.H.; Leslie, C.C. Identification of the expressed form of human cytosolic phospholipase $\mathrm{A}_{2} \beta\left(\mathrm{cPLA}_{2} \beta\right.$ ): $c \mathrm{CLA}_{2} \beta 3$ is a novel variant localized to mitochondria and early endosomes. J. Biol. Chem. 2006, 281, 16615-16624. [CrossRef]

79. Ghosh, M.; Loper, R.; Ghomashchi, F.; Tucker, D.E.; Bonventre, J.V.; Gelb, M.H.; Leslie, C.C. Function, activity, and membrane targeting of cytosolic phospholipase $\mathrm{A}_{2} \zeta$ in mouse lung fibroblasts. J. Biol. Chem. 2007, 282, 11676-11686. [CrossRef] [PubMed]

80. Clark, J.D.; Lin, L.-L.; Kriz, R.W.; Ramesha, C.S.; Sultzman, L.A.; Lin, A.Y.; Milona, N.; Knopf, J.L. A novel arachidonic acid-selective cytosolic $\mathrm{PLA}_{2}$ contains a $\mathrm{Ca}^{2+}$-dependent translocation domain with homology to PKC and GAP. Cell 1991, 65, 1043-1051. [CrossRef]

81. Lin, L.-L.; Wartmann, M.; Lin, A.Y.; Knopf, J.L.; Seth, A.; Davis, R.J. cPLA 2 is phosphorylated and activated by MAP kinase. Cell 1993, 72, 269-278. [CrossRef]

82. Casas, J.; Gijón, M.A.; Vigo, A.G.; Crespo, M.S.; Balsinde, J.; Balboa, M.A. Phosphatidylinositol 4,5-bisphosphate anchors cytosolic group IVA phospholipase $\mathrm{A}_{2}$ to perinuclear membranes and decreases its calcium requirement for translocation in live cells. Mol. Biol. Cell 2006, 17, 155-162. [CrossRef] [PubMed] 
83. Leslie, C.C. Cytosolic phospholipase $\mathrm{A}_{2}$ : Physiological function and role in disease. J. Lipid Res. 2015, 56, 1386-1402. [CrossRef] [PubMed]

84. Shimizu, T. Lipid mediators in health and disease: Enzymes and receptors as therapeutic targets for the regulation of immunity and inflammation. Annu. Rev. Pharmacol. Toxicol. 2009, 49, 123-150. [CrossRef]

85. Slatter, D.A.; Aldrovandi, M.; O’Connor, A.; Allen, S.M.; Brasher, C.J.; Murphy, R.C.; Mecklemann, S.; Ravi, S.; Darley-Usmar, V.; O'Donnell, V.B. Mapping the human platelet lipidome reveals cytosolic phospholipase $\mathrm{A}_{2}$ as a regulator of mitochondrial bioenergetics during activation. Cell Metab. 2016, 23, 930-944. [CrossRef]

86. Stahelin, R.V.; Subramanian, P.; Vora, M.; Cho, W.; Chalfant, C.E. Ceramide-1-phosphate binds group IVA cytosolic phospholipase $A_{2}$ via a novel site in the C2 domain. J. Biol. Chem. 2007, 282, 20467-20474. [CrossRef]

87. Macknight, H.P.; Stephenson, D.J.; Hoeferlin, L.A.; Benusa, S.D.; DeLigio, J.T.; Maus, K.D.; Ali, A.N.; Wayne, J.S.; Park, M.A.; Hinchcliffe, E.H.; et al. The interaction of ceramide 1-phosphate with group IVA cytosolic phospholipase $\mathrm{A}_{2}$ coordinates acute wound healing and repair. Sci. Signal. 2019, 12, eaav5918. [CrossRef]

88. Chao, C.-C.; Gutiérrez-Vázquez, C.; Rothhammer, V.; Mayo, L.; Wheeler, M.A.; Tjon, E.C.; Zandee, S.E.; Blain, M.; De Lima, K.A.; Takenaka, M.C.; et al. Metabolic control of astrocyte pathogenic activity via cPLA 2 -MAVS. Cell 2019, 179, 1483-1498.e22. [CrossRef]

89. Koundouros, N.; Karali, E.; Tripp, A.; Valle, A.; Inglese, P.; Perry, N.J.; Magee, D.J.; Virmouni, S.A.; Elder, G.A.; Tyson, A.L.; et al. Metabolic fingerprinting links oncogenic PIK3CA with enhanced arachidonic acid-derived eicosanoids. Cell 2020, 181, 1596-1611.e27. [CrossRef]

90. Ghomashchi, F.; Naika, G.S.; Bollinger, J.G.; Aloulou, A.; Lehr, M.; Leslie, C.C.; Gelb, M.H. Interfacial Kinetic and Binding Properties of mammalian group IVB phospholipase $\mathrm{A}_{2}\left(\mathrm{cPLA}_{2} \beta\right)$ and comparison with the other cPLA 2 isoforms. J. Biol. Chem. 2010, 285, 36100-36111. [CrossRef]

91. Cheng, Y.; Wang, Y.; Li, J.; Chang, I.; Wang, C.-Y. A novel read-through transcript JMJD7-PLA2G4B regulates head and neck squamous cell carcinoma cell proliferation and survival. Oncotarget 2016, 8, 1972-1982. [CrossRef]

92. Saare, M.; Tserel, L.; Haljasmägi, L.; Taalberg, E.; Peet, N.; Eimre, M.; Vetik, R.; Kingo, K.; Saks, K.; Tamm, R.; et al. Monocytes present age-related changes in phospholipid concentration and decreased energy metabolism. Aging Cell 2020, 19, e13127. [CrossRef] [PubMed]

93. Underwood, K.W.; Song, C.; Kriz, R.W.; Chang, X.J.; Knopf, J.L.; Lin, L.-L. A novel calcium-independent phospholipase $\mathrm{A}_{2}, \mathrm{CPLA}_{2} \gamma$, that is prenylated and contains homology to cPLA 2 . J. Biol. Chem. 1998, 273, 21926-21932. [CrossRef] [PubMed]

94. Asai, K.; Hirabayashi, T.; Houjou, T.; Uozumi, N.; Taguchi, R.; Shimizu, T. Human group IVC phospholipase $\mathrm{A}_{2}\left(\mathrm{CPLA}_{2} \gamma\right)$. Roles in the membrane remodeling and activation induced by oxidative stress. J. Biol. Chem. 2003, 278, 8809-8814. [CrossRef] [PubMed]

95. Lebrero, P.; Astudillo, A.M.; Rubio, J.M.; Fernández-Caballero, L.; Kokotos, G.; Balboa, M.A.; Balsinde, J. Cellular plasmalogen content does not influence arachidonic acid levels or distribution in macrophages: A role for cytosolic phospholipase $\mathrm{A}_{2} \gamma$ in phospholipid remodeling. Cells 2019, 8, 799. [CrossRef]

96. Vitale, A.; Perlin, J.; Leonelli, L.; Herr, J.; Wright, P.; Digilio, L.; Coonrod, S. Mouse cPLA $2 \gamma$, a novel oocyte and early embryo-abundant phospholipase $\mathrm{A}_{2} \gamma$-like protein, is targeted to the nuclear envelope during germinal vesicle breakdown. Dev. Biol. 2005, 282, 374-384. [CrossRef] [PubMed]

97. Su, X.; Liu, S.; Zhang, X.; Lam, S.M.; Hu, X.; Zhou, Y.; Chen, J.; Wang, Y.; Wu, C.; Shui, G.; et al. Requirement of cytosolic phospholipase $\mathrm{A}_{2} \gamma$ in lipid droplet formation. Biochim. Biophys. Acta Mol. Cell Biol. Lipids. 2017, 1862, 692-705. [CrossRef]

98. Xu, S.; Pei, R.; Guo, M.; Han, Q.; Lai, J.; Wang, Y.; Wu, C.; Zhou, Y.; Lu, M.; Chen, X. Cytosolic phospholipase $\mathrm{A}_{2} \gamma$ is involved in hepatitis $\mathrm{C}$ virus replication and assembly. J. Virol. 2012, 86, 13025-13037. [CrossRef]

99. Chiba, H.; Michibata, H.; Wakimoto, K.; Seishima, M.; Kawasaki, S.; Okubo, K.; Mitsui, H.; Torii, H.; Imai, Y. Cloning of a gene for a novel epithelium-specific cytosolic phospholipase $\mathrm{A}_{2}, \mathrm{cPLA}_{2} \delta$, induced in psoriatic skin. J. Biol. Chem. 2004, 279, 12890-12897. [CrossRef]

100. Cheung, K.L.; Jarrett, R.; Subramaniam, S.; Salimi, M.; Gutowska-Owsiak, D.; Chen, Y.-L.; Hardman, C.; Xue, L.; Cerundolo, V.; Ogg, G. Psoriatic T cells recognize neolipid antigens generated by mast cell phospholipase delivered by exosomes and presented by CD1a. J. Exp. Med. 2016, 213, 2399-2412. [CrossRef]

101. Tsuboi, K.; Uyama, T.; Okamoto, Y.; Ueda, N. Endocannabinoids and related N-acylethanolamines: Biological activities and metabolism. Inflamm. Regen. 2018, 38, 28. [CrossRef] [PubMed] 
102. Ogura, Y.; Parsons, W.H.; Kamat, S.S.; Cravatt, B.F. A calcium-dependent acyltransferase that produces N-acyl phosphatidylethanolamines. Nat. Chem. Biol. 2016, 12, 669-671. [CrossRef] [PubMed]

103. Mustafiz, S.S.B.; Uyama, T.; Morito, K.; Takahashi, N.; Kawai, K.; Hussain, Z.; Tsuboi, K.; Araki, N.; Yamamoto, K.; Tanaka, T.; et al. Intracellular $\mathrm{Ca}^{2+}$-dependent formation of $\mathrm{N}$-acyl-phosphatidylethanolamines by human cytosolic phospholipase $\mathrm{A}_{2} \varepsilon$. Biochim. Biophys. Acta Mol. Cell Biol. Lipids 2019, 1864, 158515. [CrossRef] [PubMed]

104. Binte Mustafiz, S.S.; Uyama, T.; Hussain, Z.; Kawai, K.; Tsuboi, K.; Araki, N.; Ueda, N. The role of intracellular anionic phospholipids in the production of $N$-acyl-phosphatidylethanolamines by cytosolic phospholipase $\mathrm{A}_{2} \varepsilon$. J. Biochem. 2019, 165, 343-352. [CrossRef]

105. Hussain, Z.; Uyama, T.; Kawai, K.; Mustafiz, S.S.B.; Tsuboi, K.; Earaki, N.; Ueda, N. Phosphatidylserine-stimulated production of $N$-acyl-phosphatidylethanolamines by $\mathrm{Ca}^{2+}$-dependent N-acyltransferase. Biochim. Biophys. Acta Mol. Cell Biol. Lipids 2018, 1863, 493-502. [CrossRef]

106. Capestrano, M.; Mariggio, S.; Perinetti, G.; Egorova, A.V.; Iacobacci, S.; Santoro, M.; Di Pentima, A.; Iurisci, C.; Egorov, M.V.; Di Tullio, G.; et al. Cytosolic phospholipase $\mathrm{A}_{2} \varepsilon$ drives recycling through the clathrin-independent endocytic route. J. Cell Sci. 2014, 127, 977-993. [CrossRef]

107. Everard, A.; Plovier, H.; Rastelli, M.; Van Hul, M.; D'Oplinter, A.D.W.; Geurts, L.; Druart, C.; Robine, S.; Delzenne, N.M.; Muccioli, G.G.; et al. Intestinal epithelial N-acylphosphatidylethanolamine phospholipase D links dietary fat to metabolic adaptations in obesity and steatosis. Nat. Commun. 2019, 10, 457. [CrossRef]

108. Mock, E.D.; Mustafa, M.; Gunduz-Cinar, O.; Cinar, R.; Petrie, G.N.; Kantae, V.; Di, X.; Ogasawara, D.; Varga, Z.V.; Paloczi, J.; et al. Discovery of a NAPE-PLD inhibitor that modulates emotional behavior in mice. Nat. Chem. Biol. 2020, 16, 667-675. [CrossRef]

109. Perez-Gonzalez, M.; Mendioroz, M.; Badesso, S.; Sucunza, D.; Roldan, M.; Espelosín, M.; Ursua, S.; Lujan, R.; Cuadrado-Tejedor, M.; García-Osta, A. PLA2G4E, a candidate gene for resilience in Alzheimer's disease and a new target for dementia treatment. Prog. Neurobiol. 2020, 191, 101818. [CrossRef]

110. Ghosh, M.; Tucker, D.E.; Burchett, S.A.; Leslie, C.C. Properties of the group IV phospholipase $\mathrm{A}_{2}$ family. Prog. Lipid Res. 2006, 45, 487-510. [CrossRef]

111. Moon, S.H.; Liu, X.; Cedars, A.M.; Yang, K.; Kiebish, M.A.; Joseph, S.M.; Kelley, J.; Jenkins, C.M.; Gross, R.W. Heart failure-induced activation of phospholipase $\mathrm{iPLA}_{2} \gamma$ generates hydroxyeicosatetraenoic acids opening the mitochondrial permeability transition pore. J. Biol. Chem. 2017, 293, 115-129. [CrossRef]

112. Kienesberger, P.C.; Oberer, M.; Lass, A.; Zechner, R. Mammalian patatin domain containing proteins: A family with diverse lipolytic activities involved in multiple biological functions. J. Lipid Res. 2008, 50, S63-S68. [CrossRef]

113. Ramanadham, S.; Ali, T.; Ashley, J.W.; Bone, R.N.; Hancock, W.D.; Lei, X. Calcium-independent phospholipases $A_{2}$ and their roles in biological processes and diseases. J. Lipid Res. 2015, 56, 1643-1668. [CrossRef] [PubMed]

114. Larsson, P.K.A.; Claesson, H.-E.; Kennedy, B.P. Multiple splice variants of the human calcium-independent phospholipase $\mathrm{A}_{2}$ and their effect on enzyme activity. J. Biol. Chem. 1998, 273, 207-214. [CrossRef] [PubMed]

115. Tang, J.; Kriz, R.W.; Wolfman, N.; Shaffer, M.; Seehra, J.; Jones, S.S. A novel cytosolic calcium-independent phospholipase $A_{2}$ contains eight ankyrin motifs. J. Biol. Chem. 1997, 272, 8567-8575. [CrossRef] [PubMed]

116. Malley, K.R.; Koroleva, O.; Miller, I.; Sanishvili, R.; Jenkins, C.M.; Gross, R.W.; Korolev, S. The structure of $\mathrm{iPLA}_{2} \beta$ reveals dimeric active sites and suggests mechanisms of regulation and localization. Nat. Commun. 2018, 9, 765. [CrossRef]

117. Turk, J.; White, T.D.; Nelson, A.J.; Lei, X.; Ramanadham, S. iPLA $\beta$ $\beta$ and its role in male fertility, neurological disorders, metabolic disorders, and inflammation. Biochim. Biophys. Acta Mol. Cell Biol. Lipids 2019, 1864, 846-860. [CrossRef]

118. Morgan, N.V.; Westaway, S.K.; Morton, J.E.V.; Gregory, A.; Gissen, P.; Sonek, S.; Cangul, H.; Coryell, J.; Canham, N.; Nardocci, N.; et al. PLA2G6, encoding a phospholipase $\mathrm{A}_{2}$, is mutated in neurodegenerative disorders with high brain iron. Nat. Genet. 2006, 38, 752-754. [CrossRef]

119. Zhou, Q.; Yen, A.; Rymarczyk, G.; Asai, H.; Trengrove, C.; Aziz, N.; Kirber, M.T.; Mostoslavsky, G.; Ikezu, T.; Wolozin, B.; et al. Impairment of PARK14-dependent $\mathrm{Ca}^{2+}$ signalling is a novel determinant of Parkinson's disease. Nat. Commun. 2016, 7, 10332. [CrossRef] [PubMed] 
120. Kinghorn, K.J.; Castillo-Quan, J.I.; Bartolome, F.; Angelova, P.R.; Li, L.; Pope, S.; Cochemé, H.M.; Khan, S.; Asghari, S.; Bhatia, K.P.; et al. Loss of PLA2G6 leads to elevated mitochondrial lipid peroxidation and mitochondrial dysfunction. Brain 2015, 138, 1801-1816. [CrossRef]

121. Lin, G.; Lee, P.-T.; Chen, K.; Mao, D.; Tan, K.L.; Zuo, Z.; Lin, W.-W.; Wang, L.; Bellen, H.J. Phospholipase PLA2G6, a parkinsonism-associated gene, affects Vps26 and Vps35, retromer function, and ceramide levels, similar to $\alpha$-synuclein gain. Cell Metab. 2018, 28, 605-618.e6. [CrossRef]

122. Mori, A.; Hatano, T.; Inoshita, T.; Shiba-Fukushima, K.; Koinuma, T.; Meng, H.; Kubo, S.-I.; Spratt, S.; Cui, C.; Yamashita, C.; et al. Parkinson's disease-associated $P L A_{2}-V I A / P L A 2 G 6$ regulates neuronal functions and $\alpha$-synuclein stability through membrane remodeling. Proc. Natl. Acad. Sci. USA 2019, 116, 20689-20699. [CrossRef] [PubMed]

123. Deng, X.; Wang, J.; Jiao, L.; Utaipan, T.; Tuma-Kellner, S.; Schmitz, G.; Liebisch, G.; Stremmel, W.; Chamulitrat, W. iPLA $2 \beta$ deficiency attenuates obesity and hepatic steatosis in $o b / o b$ mice through hepatic fatty-acyl phospholipid remodeling. Biochim. Biophys. Acta Mol. Cell Biol. Lipids 2016, 1861, 449-461. [CrossRef]

124. Jiao, L.; Gan-Schreier, H.; Zhu, X.; Wei, W.; Tuma-Kellner, S.; Liebisch, G.; Stremmel, W.; Chamulitrat, W. Ageing sensitized by iPLA $\beta$ deficiency induces liver fibrosis and intestinal atrophy involving suppression of homeostatic genes and alteration of intestinal lipids and bile acids. Biochim. Biophys. Acta Mol. Cell Biol. Lipids 2017, 1862, 1520-1533. [CrossRef]

125. Otto, A.-C.; Gan-Schreier, H.; Zhu, X.; Tuma-Kellner, S.; Staffer, S.; Ganzha, A.; Liebisch, G.; Chamulitrat, W. Group VIA phospholipase $\mathrm{A}_{2}$ deficiency in mice chronically fed with high-fat-diet attenuates hepatic steatosis by correcting a defect of phospholipid remodeling. Biochim. Biophys. Acta Mol. Cell Biol. Lipids 2019, 1864, 662-676. [CrossRef] [PubMed]

126. Zhu, X.; Gan-Schreier, H.; Otto, A.-C.; Cheng, Y.; Staffer, S.; Tuma-Kellner, S.; Ganzha, A.; Liebisch, G.; Chamulitrat, W. iPLA $2 \beta$ deficiency in mice fed with MCD diet does not correct the defect of phospholipid remodeling but attenuates hepatocellular injury via an inhibition of lipid uptake genes. Biochim. Biophys. Acta Mol. Cell Biol. Lipids 2019, 1864, 677-687. [CrossRef]

127. Liu, X.; Moon, S.H.; Jenkins, C.M.; Sims, H.F.; Gross, R.W. Cyclooxygenase-2 mediated oxidation of 2-arachidonoyl-lysophospholipids identifies unknown lipid signaling pathways. Cell Chem. Biol. 2016, 23, 1217-1227. [CrossRef]

128. Moon, S.H.; Jenkins, C.M.; Liu, X.; Guan, S.; Mancuso, D.J.; Gross, R.W. Activation of mitochondrial calcium-independent phospholipase $\mathrm{A}_{2} \gamma\left(\mathrm{iPLA}_{2} \gamma\right)$ by divalent cations mediating arachidonate release and production of downstream eicosanoids. J. Biol. Chem. 2012, 287, 14880-14895. [CrossRef] [PubMed]

129. Mancuso, D.J.; Sims, H.F.; Han, X.; Jenkins, C.M.; Guan, S.P.; Yang, K.; Moon, S.H.; Pietka, T.; Abumrad, N.A.; Schlesinger, P.H.; et al. Genetic ablation of calcium-independent phospholipase $\mathrm{A}_{2} \gamma$ leads to alterations in mitochondrial lipid metabolism and function resulting in a deficient mitochondrial bioenergetic phenotype. J. Biol. Chem. 2007, 282, 34611-34622. [CrossRef] [PubMed]

130. Bione, S.; D'Adamo, P.; Maestrini, E.; Gedeon, A.K.; Bolhuis, P.A.; Toniolo, D. A novel X-linked gene, G4.5. is responsible for Barth syndrome. Nat. Genet. 1996, 12, 385-389. [CrossRef] [PubMed]

131. Saunders, C.J.; Moon, S.H.; Liu, X.; Thiffault, I.; Coffman, K.; LePichon, J.B.; Taboada, E.; Smith, L.D.; Farrow, E.G.; Miller, N.; et al. Loss of function variants in human PNPLA8 encoding calcium-independent phospholipase $\mathrm{A}_{2} \gamma$ recapitulate the mitochondriopathy of the homologous null mouse. Hum. Mutat. 2015, 36, 301-306. [CrossRef] [PubMed]

132. Yoda, E.; Rai, K.; Ogawa, M.; Takakura, Y.; Kuwata, H.; Suzuki, H.; Nakatani, Y.; Murakami, M.; Hara, S. Group VIB Calcium-independent phospholipase $\mathrm{A}_{2}\left(\mathrm{iPLA}_{2} \gamma\right)$ regulates platelet activation, hemostasis and thrombosis in mice. PLoS ONE 2014, 9, e109409. [CrossRef]

133. Moon, S.H.; Mancuso, D.J.; Sims, H.F.; Liu, X.; Nguyen, A.L.; Yang, K.; Guan, S.; Dilthey, B.G.; Jenkins, C.M.; Weinheimer, C.J.; et al. Cardiac myocyte-specific knock-out of calcium-independent phospholipase $\mathrm{A}_{2} \gamma$ $\left(\mathrm{iPLA}_{2} \gamma\right)$ decreases oxidized fatty acids during ischemia/reperfusion and reduces infarct size. J. Biol. Chem. 2016, 291, 19687-19700. [CrossRef] [PubMed]

134. Liu, G.-Y.; Moon, S.H.; Jenkins, C.M.; Li, M.; Sims, H.F.; Guan, S.; Gross, R.W. The phospholipase iPLA $2 \gamma$ is a major mediator releasing oxidized aliphatic chains from cardiolipin, integrating mitochondrial bioenergetics and signaling. J. Biol. Chem. 2017, 292, 10672-10684. [CrossRef] [PubMed] 
135. Liu, X.; Sims, H.F.; Jenkins, C.M.; Guan, S.; Dilthey, B.G.; Gross, R.W. 12-LOX catalyzes the oxidation of 2-arachidonoyl-lysolipids in platelets generating eicosanoid-lysolipids that are attenuated by iPLA $2 \gamma$ knockout. J. Biol. Chem. 2020, 295, 5307-5320. [CrossRef] [PubMed]

136. Kienesberger, P.C.; Lass, A.; Preiss-Landl, K.; Wolinski, H.; Kohlwein, S.D.; Zimmermann, R.; Zechner, R. Identification of an insulin-regulated lysophospholipase with homology to neuropathy target esterase. $J$. Biol. Chem. 2007, 283, 5908-5917. [CrossRef] [PubMed]

137. Quistad, G.B.; Barlow, C.; Winrow, C.J.; Sparks, S.E.; Casida, J.E. Evidence that mouse brain neuropathy target esterase is a lysophospholipase. Proc. Natl. Acad. Sci. USA 2003, 100, 7983-7987. [CrossRef]

138. Winrow, C.J.; Hemming, M.L.; Allen, D.M.; Quistad, G.B.; Casida, J.E.; Barlow, C. Loss of neuropathy target esterase in mice links organophosphate exposure to hyperactivity. Nat. Genet. 2003, 33, 477-485. [CrossRef]

139. Gallazzini, M.; Ferraris, J.D.; Kunin, M.; Morris, R.G.; Burg, M.B. Neuropathy target esterase catalyzes osmoprotective renal synthesis of glycerophosphocholine in response to high NaCl. Proc. Natl. Acad. Sci. USA 2006, 103, 15260-15265. [CrossRef]

140. Akassoglou, K.; Malester, B.; Xu, J.; Tessarollo, L.; Rosenbluth, J.; Chao, M.V. Brain-specific deletion of neuropathy target esterase/swisscheese results in neurodegeneration. Proc. Natl. Acad. Sci. USA 2004, 101, 5075-5080. [CrossRef]

141. Moser, M.; Li, Y.; Vaupel, K.; Kretzschmar, D.; Kluge, R.; Glynn, P.; Buettner, R. Placental failure and impaired vasculogenesis result in embryonic lethality for neuropathy target esterase-deficient mice. Mol. Cell. Biol. 2004, 24, 1667-1679. [CrossRef]

142. Read, D.J.; Li, Y.; Chao, M.V.; Cavanagh, J.B.; Glynn, P. Neuropathy target esterase is required for adult vertebrate axon maintenance. J. Neurosci. 2009, 29, 11594-11600. [CrossRef] [PubMed]

143. Rainier, S.; Bui, M.; Mark, E.; Thomas, D.; Tokarz, D.; Ming, L.; Delaney, C.E.; Richardson, R.J.; Albers, J.W.; Matsunami, N.; et al. Neuropathy target esterase gene mutations cause motor neuron disease. Am. J. Hum. Genet. 2008, 82, 780-785. [CrossRef]

144. Kmoch, S.; Majewski, J.; Ramamurthy, V.; Cao, S.; Fahiminiya, S.; Ren, H.; MacDonald, I.M.; Lopez, I.; Sun, V.; Keser, V.; et al. Mutations in PNPLA6 are linked to photoreceptor degeneration and various forms of childhood blindness. Nat. Commun. 2015, 6, 5614. [CrossRef] [PubMed]

145. Heier, C.; Kien, B.; Huang, F.; Eichmann, T.O.; Xie, H.; Zechner, R.; Chang, P.-A. The phospholipase PNPLA7 functions as a lysophosphatidylcholine hydrolase and interacts with lipid droplets through its catalytic domain. J. Biol. Chem. 2017, 292, 19087-19098. [CrossRef] [PubMed]

146. Huang, Y.; He, S.; Li, J.Z.; Seo, Y.-K.; Osborne, T.F.; Cohen, J.C.; Hobbs, H.H. A feed-forward loop amplifies nutritional regulation of PNPLA3. Proc. Natl. Acad. Sci. USA 2010, 107, 7892-7897. [CrossRef]

147. Zimmermann, R.; Strauss, J.G.; Haemmerle, G.; Schoiswohl, G.; Birner-Gruenberger, R.; Riederer, M.; Lass, A.; Neuberger, G.; Eisenhaber, F.; Hermetter, A.; et al. Fat Mobilization in adipose tissue Is promoted by adipose triglyceride lipase. Science 2004, 306, 1383-1386. [CrossRef]

148. Girousse, A.; Tavernier, G.; Valle, C.; Moro, C.; Mejhert, N.; Dinel, A.-L.; Houssier, M.; Roussel, B.; Besse-Patin, A.; Combes, M.; et al. Partial inhibition of adipose tissue lipolysis improves glucose metabolism and insulin sensitivity without alteration of fat mass. PLoS Biol. 2013, 11, e1001485. [CrossRef]

149. Haemmerle, G.; Busemann, H.; Young, A.F.; Alexander, C.M.O.; Hoppe, P.; Mukhopadhyay, S.; Nittler, L.R. Lipolysis and Altered energy metabolism in mice lacking adipose triglyceride lipase. Science 2006, 312, 734-737. [CrossRef]

150. Das, S.K.; Eder, S.; Schauer, S.; Diwoky, C.; Temmel, H.; Guertl, B.; Gorkiewicz, G.; Tamilarasan, K.P.; Kumari, P.; Trauner, M.; et al. Adipose triglyceride lipase contributes to cancer-associated cachexia. Science 2011, 333, 233-238. [CrossRef]

151. Haemmerle, G.; Moustafa, T.; Woelkart, G.; Büttner, S.; Schmidt, A.; Van De Weijer, T.; Hesselink, M.; Jaeger, D.; Kienesberger, P.C.; Zierler, K.; et al. ATGL-mediated fat catabolism regulates cardiac mitochondrial function via PPAR- $\alpha$ and PGC-1. Nat. Med. 2011, 17, 1076-1085. [CrossRef]

152. Yang, X.; Lu, X.; Lombes, M.; Rha, G.B.; Chi, Y.I.; Guerin, T.M.; Smart, E.J.; Liu, J. The G0/G1 switch gene 2 regulates adipose lipolysis through association with adipose triglyceride lipase. Cell Metab. 2010, 11, 194-205. [CrossRef] [PubMed]

153. Schlager, S.; Goeritzer, M.; Jandl, K.; Frei, R.; Vujic, N.; Kolb, D.; Strohmaier, H.; Dorow, J.; Eichmann, T.O.; Rosenberger, A.; et al. Adipose triglyceride lipase acts on neutrophil lipid droplets to regulate substrate availability for lipid mediator synthesis. J. Leukoc. Biol. 2015, 98, 837-850. [CrossRef] 
154. Sugihara, M.; Morito, D.; Ainuki, S.; Hirano, Y.; Ogino, K.; Kitamura, A.; Hirata, H.; Nagata, K. The AAA+ ATPase/ubiquitin ligase mysterin stabilizes cytoplasmic lipid droplets. J. Cell Biol. 2019, 218, 949-960. [CrossRef]

155. Heckmann, B.L.; Zhang, X.; Xie, X.; Saarinen, A.; Lu, X.; Yang, X.; Liu, J. Defective adipose lipolysis and altered global energy metabolism in mice with adipose overexpression of the lipolytic inhibitor G0/G1 switch gene 2 (G0S2). J. Biol. Chem. 2014, 289, 1905-1916. [CrossRef] [PubMed]

156. Lass, A.; Zimmermann, R.; Haemmerle, G.; Riederer, M.; Schoiswohl, G.; Schweiger, M.; Kienesberger, P.; Strauss, J.G.; Gorkiewicz, G.; Zechner, R. Adipose triglyceride lipase-mediated lipolysis of cellular fat stores is activated by CGI-58 and defective in Chanarin-Dorfman Syndrome. Cell Metab. 2006, 3, 309-319. [CrossRef]

157. Demerjian, M.; Crumrine, D.A.; Milstone, L.M.; Williams, M.L.; Elias, P.M. Barrier dysfunction and pathogenesis of neutral lipid storage disease with ichthyosis (Chanarin-Dorfman Syndrome). J. Investig. Dermatol. 2006, 126, 2032-2038. [CrossRef] [PubMed]

158. Lass, A.; Zimmermann, R.; Oberer, M.; Zechner, R. Lipolysis-A highly regulated multi-enzyme complex mediates the catabolism of cellular fat stores. Prog. Lipid Res. 2011, 50, 14-27. [CrossRef]

159. Young, S.G.; Zechner, R. Biochemistry and pathophysiology of intravascular and intracellular lipolysis. Genes Dev. 2013, 27, 459-484. [CrossRef]

160. Romeo, S.; Kozlitina, J.; Xing, C.; Pertsemlidis, A.; Cox, D.; Pennacchio, L.A.; Boerwinkle, E.; Cohen, J.C.; Hobbs, H.H. Genetic variation in PNPLA3 confers susceptibility to nonalcoholic fatty liver disease. Nat. Genet. 2008, 40, 1461-1465. [CrossRef]

161. Basantani, M.K.; Sitnick, M.T.; Cai, L.; Brenner, D.S.; Gardner, N.P.; Li, J.Z.; Schoiswohl, G.; Yang, K.; Kumari, M.; Gross, R.W.; et al. Pnpla3/Adiponutrin deficiency in mice does not contribute to fatty liver disease or metabolic syndrome. J. Lipid Res. 2011, 52, 318-329. [CrossRef]

162. Smagris, E.; Basuray, S.; Li, J.; Huang, Y.; Lai, K.-M.V.; Gromada, J.; Cohen, J.C.; Hobbs, H.H. Pnpla3I148M knockin mice accumulate PNPLA3 on lipid droplets and develop hepatic steatosis. Hepatology 2014, 61, 108-118. [CrossRef] [PubMed]

163. Li, J.Z.; Huang, Y.; Karaman, R.; Ivanova, P.T.; Brown, H.A.; Roddy, T.; Castro-Perez, J.; Cohen, J.C.; Hobbs, H.H. Chronic overexpression of PNPLA3 ${ }^{\mathrm{I} 148 \mathrm{M}}$ in mouse liver causes hepatic steatosis. J. Clin. Investig. 2012, 122, 4130-4144. [CrossRef]

164. Mitsche, M.A.; Hobbs, H.H.; Cohen, J.C. Patatin-like phospholipase domain-containing protein 3 promotes transfers of essential fatty acids from triglycerides to phospholipids in hepatic lipid droplets. J. Biol. Chem. 2018, 293, 6958-6968. [CrossRef] [PubMed]

165. Pirazzi, C.; Valenti, L.; Motta, B.M.; Pingitore, P.; Hedfalk, K.; Mancina, R.M.; Burza, M.A.; Indiveri, C.; Ferro, Y.; Montalcini, T.; et al. PNPLA3 has retinyl-palmitate lipase activity in human hepatic stellate cells. Hum. Mol. Genet. 2014, 23, 4077-4085. [CrossRef] [PubMed]

166. Wang, Y.; Kory, N.; Basuray, S.; Cohen, J.C.; Hobbs, H.H. PNPLA3, CGI-58, and inhibition of hepatic triglyceride hydrolysis in mice. Hepatology 2019, 69, 2427-2441. [CrossRef] [PubMed]

167. Yang, A.; Mottillo, E.P.; Mladenovic-Lucas, L.; Zhou, L.; Granneman, J.G. Dynamic interactions of ABHD5 with PNPLA3 regulate triacylglycerol metabolism in brown adipocytes. Nat. Metab. 2019, 1, 560-569. [CrossRef] [PubMed]

168. Grall, A.; Guaguere, E.; Planchais, S.; Grond, S.; Bourrat, E.; Hausser, I.; Hitte, C.; Le Gallo, M.; Derbois, C.; Kim, G.-J.; et al. PNPLA1 mutations cause autosomal recessive congenital ichthyosis in golden retriever dogs and humans. Nat. Genet. 2012, 44, 140-147. [CrossRef]

169. Grond, S.; Eichmann, T.O.; Dubrac, S.; Kolb, D.; Schmuth, M.; Fischer, J.; Crumrine, D.; Elias, P.M.; Haemmerle, G.; Zechner, R.; et al. PNPLA1 deficiency in mice and humans leads to a defect in the synthesis of omega-O-acylceramides. J. Investig. Dermatol. 2017, 137, 394-402. [CrossRef] [PubMed]

170. Hirabayashi, T.; Anjo, T.; Kaneko, A.; Senoo, Y.; Shibata, A.; Takama, H.; Yokoyama, K.; Nishito, Y.; Ono, T.; Taya, C.; et al. PNPLA1 has a crucial role in skin barrier function by directing acylceramide biosynthesis. Nat. Commun. 2017, 8, 14609. [CrossRef]

171. Ohno, Y.; Kamiyama, N.; Nakamichi, S.; Kihara, A. PNPLA1 is a transacylase essential for the generation of the skin barrier lipid $\omega$-O-acylceramide. Nat. Commun. 2017, 8, 14610. [CrossRef] [PubMed]

172. Kien, B.; Grond, S.; Haemmerle, G.; Lass, A.; Eichmann, T.O.; Radner, F.P.W. ABHD5 stimulates PNPLA1-mediated $\omega$-O-acylceramide biosynthesis essential for a functional skin permeability barrier. J. Lipid Res. 2018, 59, 2360-2367. [CrossRef] 
173. Ohno, Y.; Nara, A.; Nakamichi, S.; Kihara, A. Molecular mechanism of the ichthyosis pathology of Chanarin-Dorfman syndrome: Stimulation of PNPLA1-catalyzed $\omega$-O-acylceramide production by ABHD5. J. Dermatol. Sci. 2018, 92, 245-253. [CrossRef] [PubMed]

174. Hirabayashi, T.; Murakami, M.; Kihara, A. The role of PNPLA1 in $\omega$-O-acylceramide synthesis and skin barrier function. Biochim. Biophys. Acta Mol. Cell Biol. Lipids 2019, 1864, 869-879. [CrossRef]

175. Hattori, M.; Arai, H. Intracellular PAF-acetylhydrolase type I. Enzymes 2015, 38, 23-36. [CrossRef]

176. Kono, N.; Arai, H. Intracellular Platelet-activating factor acetylhydrolase, type II. Enzymes 2015, 38, 43-54. [CrossRef] [PubMed]

177. Tjoelker, L.W.; Wilder, C.; Eberhardt, C.; Stafforinit, D.M.; Dietsch, G.; Schimpf, B.; Hooper, S.; Le Trong, H.; Cousens, L.S.; Zimmerman, G.A.; et al. Anti-inflammatory properties of a platelet-activating factor acetylhydrolase. Nat. Cell Biol. 1995, 374, 549-553. [CrossRef]

178. Jiang, Z.; Fehrenbach, M.L.; Ravaioli, G.; Kokalari, B.; Redai, I.G.; Sheardown, S.A.; Wilson, S.; Macphee, C.H.; Haczku, A. The effect of lipoprotein-associated phospholipase $A_{2}$ deficiency on pulmonary allergic responses in aspergillus fumigatus sensitized mice. Respir. Res. 2012, 13, 100. [CrossRef]

179. Corson, M.A. Phospholipase $A_{2}$ inhibitors in atherosclerosis: The race is on. Lancet 2009, 373, 608-610. [CrossRef]

180. Wilensky, R.L.; Shi, Y.; Mohler, E.R.; Hamamdzic, D.; Burgert, M.E.; Li, J.; Postle, A.; Fenning, R.S.; Bollinger, J.G.; Hoffman, B.E.; et al. Inhibition of lipoprotein-associated phospholipase $\mathrm{A}_{2}$ reduces complex coronary atherosclerotic plaque development. Nat. Med. 2008, 14, 1059-1066. [CrossRef]

181. O’Donoghue, M.L.; Braunwald, E.; White, H.D.; Steen, D.P.; Lukas, M.A.; Tarka, E.; Steg, P.G.; Hochman, J.S.; Bode, C.; Maggioni, A.P.; et al. Effect of darapladib on major coronary events after an acute coronary syndrome. JAMA 2014, 312, 1006-1015. [CrossRef] [PubMed]

182. Acharya, N.K.; Levin, E.; Clifford, P.M.; Han, M.; Tourtellotte, R.; Chamberlain, D.; Pollaro, M.; Coretti, N.J.; Kosciuk, M.C.; Nagele, E.P.; et al. Diabetes and hypercholesterolemia increase blood-brain barrier permeability and brain amyloid deposition: Beneficial effects of the LPPLA 2 inhibitor darapladib. J. Alzheimer's Dis. 2013, 35, 179-198. [CrossRef]

183. Canning, P.; Kenny, B.-A.; Prise, V.; Glenn, J.; Sarker, M.H.; Hudson, N.; Brandt, M.; Lopez, F.J.; Gale, D.; Luthert, P.J.; et al. Lipoprotein-associated phospholipase $\mathrm{A}_{2}\left(\mathrm{Lp}-\mathrm{PLA}_{2}\right)$ as a therapeutic target to prevent retinal vasopermeability during diabetes. Proc. Natl. Acad. Sci. USA 2016, 113, 7213-7218. [CrossRef] [PubMed]

184. Xu, C.; Reichert, E.C.; Nakano, T.; Lohse, M.; Gardner, A.A.; Revelo, M.P.; Topham, M.K.; Stafforini, D.M. Deficiency of phospholipase $\mathrm{A}_{2}$ group 7 decreases intestinal polyposis and colon tumorigenesis in $\mathrm{Apc}^{\mathrm{Min} /+}$ mice. Cancer Res. 2013, 73, 2806-2816. [CrossRef]

185. Hattori, M.; Adachi, H.; Tsujimoto, M.; Arai, H.; Inoue, K. Miller-Dieker lissencephaly gene encodes a subunit of brain platelet-activating factor. Nat. Cell Biol. 1994, 370, 216-218. [CrossRef]

186. Koizumi, H.; Yamaguchi, N.; Hattori, M.; Ishikawa, T.-O.; Aoki, J.; Taketo, M.M.; Inoue, K.; Arai, H. Targeted disruption of intracellular type I platelet activating factor-acetylhydrolase catalytic subunits causes severe impairment in spermatogenesis. J. Biol. Chem. 2003, 278, 12489-12494. [CrossRef]

187. Page, R.M.; Münch, A.; Horn, T.; Kuhn, P.-H.; Colombo, A.; Reiner, O.; Boutros, M.; Steiner, H.; Lichtenthaler, S.F.; Haass, C. Loss of PAFAH1B2 reduces amyloid- $\beta$ generation by promoting the degradation of amyloid precursor protein C-terminal fragments. J. Neurosci. 2012, 32, 18204-18214. [CrossRef] [PubMed]

188. Livnat, I.; Finkelshtein, D.; Ghosh, I.; Arai, H.; Reiner, O. PAF-AH catalytic subunits modulate the Wnt pathway in developing GABAergic neurons. Front. Cell. Neurosci. 2010, 4, 19. [CrossRef] [PubMed]

189. Kono, N.; Inoue, T.; Yoshida, Y.; Sato, H.; Matsusue, T.; Itabe, H.; Niki, E.; Aoki, J.; Arai, H. Protection against oxidative stress-induced hepatic injury by intracellular type II platelet-activating factor acetylhydrolase by metabolism of oxidized phospholipids in vivo. J. Biol. Chem. 2007, 283, 1628-1636. [CrossRef] [PubMed]

190. Shimanaka, Y.; Kono, N.; Taketomi, Y.; Arita, M.; Okayama, Y.; Tanaka, Y.; Nishito, Y.; Mochizuki, T.; Kusuhara, H.; Adibekian, A.; et al. Omega-3 fatty acid epoxides are autocrine mediators that control the magnitude of IgE-mediated mast cell activation. Nat. Med. 2017, 23, 1287-1297. [CrossRef]

191. Kono, N.; Arai, H. Platelet-activating factor acetylhydrolases: An overview and update. Biochim. Biophys. Acta Mol. Cell Biol. Lipids 2019, 1864, 922-931. [CrossRef] [PubMed]

192. Abe, A.; Hiraoka, M.; Wild, S.; Wilcoxen, S.E.; Paine, R.; Shayman, J.A. Lysosomal phospholipase $\mathrm{A}_{2}$ is selectively expressed in alveolar macrophages. J. Biol. Chem. 2004, 279, 42605-42611. [CrossRef] 
193. Hiraoka, M.; Abe, A.; Lu, Y.; Yang, K.; Han, X.; Gross, R.W.; Shayman, J.A. Lysosomal phospholipase $\mathrm{A}_{2}$ and phospholipidosis. Mol. Cell. Biol. 2006, 26, 6139-6148. [CrossRef]

194. Paduraru, C.; Bezbradica, J.S.; Kunte, A.; Kelly, R.; Shayman, J.A.; Veerapen, N.; Cox, L.R.; Besra, G.S.; Cresswell, P. Role for lysosomal phospholipase $\mathrm{A}_{2}$ in iNKT cell-mediated CD1d recognition. Proc. Natl. Acad. Sci. USA 2013, 110, 5097-5102. [CrossRef] [PubMed]

195. Schneider, B.; Behrends, J.; Hagens, K.; Harmel, N.; Shayman, J.A.; Schaible, U.E. Lysosomal phospholipase $\mathrm{A}_{2}$ : A novel player in host immunity to Mycobacterium tuberculosis. Eur. J. Immunol. 2014, 44, 2394-2404. [CrossRef] [PubMed]

196. Fisher, A.B.; Dodia, C.; Feinstein, S.I.; Ho, Y.-S. Altered lung phospholipid metabolism in mice with targeted deletion of lysosomal-type phospholipase A2. J. Lipid Res. 2005, 46, 1248-1256. [CrossRef] [PubMed]

197. Vázquez-Medina, J.P.; Tao, J.-Q.; Patel, P.; Bannitz-Fernandes, R.; Dodia, C.; Sorokina, E.M.; Feinstein, S.I.; Chatterjee, S.; Fisher, A.B. Genetic inactivation of the phospholipase $\mathrm{A}_{2}$ activity of peroxiredoxin 6 in mice protects against LPS-induced acute lung injury. Am. J. Physiol. Cell. Mol. Physiol. 2019, 316, L656-L668. [CrossRef]

198. Fisher, A.B.; Vasquez-Medina, J.P.; Dodia, C.; Sorokina, E.M.; Tao, J.-Q.; Feinstein, S.I. Peroxiredoxin 6 phospholipid hydroperoxidase activity in the repair of peroxidized cell membranes. Redox Biol. 2017, 14, 41-46. [CrossRef]

199. Moawad, A.R.; Fernandez, M.C.; Scarlata, E.; Dodia, C.; Feinstein, S.I.; Fisher, A.B.; O'Flaherty, C. Deficiency of peroxiredoxin 6 or inhibition of its phospholipase $A_{2}$ activity impair the in vitro sperm fertilizing competence in mice. Sci. Rep. 2017, 7, 12994. [CrossRef]

200. Fisher, A.B. The phospholipase $A_{2}$ activity of peroxiredoxin 6. J. Lipid Res. 2018, 59, 1132-1147. [CrossRef]

201. Shayman, J.A.; Tesmer, J.J.G. Lysosomal phospholipase $\mathrm{A}_{2}$. Biochim. Biophys. Acta Mol. Cell Biol. Lipids 2019, 1864, 932-940. [CrossRef] [PubMed]

202. Uyama, T.; Ikematsu, N.; Inoue, M.; Shinohara, N.; Jin, X.-H.; Tsuboi, K.; Tonai, T.; Tokumura, A.; Ueda, N. Generation of $N$-acylphosphatidylethanolamine by members of the phospholipase A/acyltransferase (PLA/AT) Family. J. Biol. Chem. 2012, 287, 31905-31919. [CrossRef] [PubMed]

203. Jaworski, K.; Ahmadian, M.; Duncan, R.E.; Sarkadi-Nagy, E.; Varady, K.A.; Hellerstein, M.K.; Lee, H.-Y.; Samuel, V.T.; Shulman, G.I.; Kim, K.-H.; et al. AdPLA ablation increases lipolysis and prevents obesity induced by high-fat feeding or leptin deficiency. Nat. Med. 2009, 15, 159-168. [CrossRef]

204. Zhang, S.-Y.; Dong, Y.-Q.; Wang, P.; Zhang, X.; Yan, Y.; Sun, L.; Liu, B.; Zhang, D.; Zhang, H.; Liu, H.; et al. Adipocyte-derived lysophosphatidylcholine activates adipocyte and adipose tissue macrophage Nod-like receptor protein 3 inflammasomes mediating homocysteine-induced insulin resistance. EBioMedicine 2018, 31, 202-216. [CrossRef]

205. Xiong, S.; Tu, H.; Kollareddy, M.; Pant, V.; Li, Q.; Zhang, Y.; Jackson, J.G.; Suh, Y.-A.; Elizondo-Fraire, A.C.; Yang, P.; et al. Pla2g16 phospholipase mediates gain-of-function activities of mutant p53. Proc. Natl. Acad. Sci. USA 2014, 111, 11145-11150. [CrossRef]

206. Golczak, M.; Sears, A.E.; Kiser, P.D.; Palczewski, K. LRAT-specific domain facilitates vitamin A metabolism by domain swapping in HRASLS3. Nat. Chem. Biol. 2014, 11, 26-32. [CrossRef]

207. Uyama, T.; Kawai, K.; Kono, N.; Watanabe, M.; Tsuboi, K.; Inoue, T.; Araki, N.; Arai, H.; Ueda, N. Interaction of phospholipase A/acyltransferase-3 with Pex19p: A possible involvement in the down-regulation of peroxisomes. J. Biol. Chem. 2015, 290, 17520-17534. [CrossRef] [PubMed]

208. Staring, J.; Von Castelmur, E.; Blomen, V.A.; Hengel, L.G.V.D.; Brockmann, M.; Baggen, J.; Thibaut, H.J.; Nieuwenhuis, J.; Janssen, H.; Van Kuppeveld, F.J.M.; et al. PLA2G16 represents a switch between entry and clearance of Picornaviridae. Nat. Cell Biol. 2017, 541, 412-416. [CrossRef]

209. Hussain, Z.; Uyama, T.; Tsuboi, K.; Ueda, N. Mammalian enzymes responsible for the biosynthesis of $\mathrm{N}$-acylethanolamines. Biochim. Biophys. Acta Mol. Cell Biol. Lipids 2017, 1862, 1546-1561. [CrossRef]

210. Mardian, E.B.; Bradley, R.M.; Duncan, R.E. The HRASLS (PLA/AT) subfamily of enzymes. J. Biomed. Sci. 2015, 22, 99. [CrossRef]

211. Thomas, G.; Brown, A.L.; Brown, J.M. In vivo metabolite profiling as a means to identify uncharacterized lipase function: Recent success stories within the alpha beta hydrolase domain (ABHD) enzyme family. Biochim. Biophys. Acta Mol. Cell Biol. Lipids 2014, 1841, 1097-1101. [CrossRef] [PubMed] 
212. Long, J.Z.; Cisar, J.S.; Milliken, D.; Niessen, S.; Wang, C.; Trauger, S.A.; Siuzdak, G.; Cravatt, B.F. Metabolomics annotates ABHD3 as a physiologic regulator of medium-chain phospholipids. Nat. Chem. Biol. 2011, 7, 763-765. [CrossRef]

213. Lee, H.-C.; Simon, G.M.; Cravatt, B.F. ABHD4 regulates multiple classes of $N$-acyl phospholipids in the mammalian central nervous system. Biochemistry 2015, 54, 2539-2549. [CrossRef]

214. Marrs, W.R.; Blankman, J.L.; Horne, E.A.; Thomazeau, A.; Lin, Y.H.; Coy, J.; Bodor, A.L.; Muccioli, G.G.; Hu, S.S.-J.; Woodruff, G.; et al. The serine hydrolase ABHD6 controls the accumulation and efficacy of 2-AG at cannabinoid receptors. Nat. Neurosci. 2010, 13, 951-957. [CrossRef] [PubMed]

215. Blankman, J.L.; Long, J.Z.; Trauger, S.A.; Siuzdak, G.; Cravatt, B.F. ABHD12 controls brain lysophosphatidylserine pathways that are deregulated in a murine model of the neurodegenerative disease PHARC. Proc. Natl. Acad. Sci. USA 2013, 110, 1500-1505. [CrossRef] [PubMed]

216. Fiskerstrand, T.; Brahim, D.H.-B.; Johansson, S.; M'Zahem, A.; Haukanes, B.I.; Drouot, N.; Zimmermann, J.; Cole, A.J.; Vedeler, C.; Bredrup, C.; et al. Mutations in ABHD12 cause the neurodegenerative disease PHARC: An inborn error of endocannabinoid metabolism. Am. J. Hum. Genet. 2010, 87, 410-417. [CrossRef]

217. Kamat, S.S.; Camara, K.; Parsons, W.H.; Chen, D.-H.; Dix, M.M.; Bird, T.D.; Howell, A.R.; Cravatt, B.F. Immunomodulatory lysophosphatidylserines are regulated by ABHD16A and ABHD12 interplay. Nat. Chem. Biol. 2015, 11, 164-171. [CrossRef]

218. Maeda, Y.; Tashima, Y.; Houjou, T.; Fujita, M.; Yoko-o, T.; Jigami, Y.; Taguchi, R.; Kinoshita, T. Fatty acid remodeling of GPI-anchored proteins is required for their raft association. Mol. Biol. Cell 2007, 18, 1497-1506. [CrossRef]

219. Wang, Y.; Murakami, Y.; Yasui, T.; Wakana, S.; Kikutani, H.; Kinoshita, T.; Maeda, Y. Significance of glycosylphosphatidylinositol-anchored protein enrichment in lipid rafts for the control of autoimmunity. $J$. Biol. Chem. 2013, 288, 25490-25499. [CrossRef]

220. Lee, G.-H.; Fujita, M.; Takaoka, K.; Murakami, Y.; Fujihara, Y.; Kanzawa, N.; Murakami, K.-I.; Kajikawa, E.; Takada, Y.; Saito, K.; et al. A GPI processing phospholipase A2, PGAP6, modulates Nodal signaling in embryos by shedding CRIPTO. J. Cell Biol. 2016, 215, 705-718. [CrossRef]

221. Nikolaou, A.; Kokotou, M.G.; Vasilakaki, S.; Kokotos, G. Small-molecule inhibitors as potential therapeutics and as tools to understand the role of phospholipases $\mathrm{A}_{2}$. Biochim. Biophys. Acta Mol. Cell Biol. Lipids 2019, 1864, 941-956. [CrossRef]

Publisher's Note: MDPI stays neutral with regard to jurisdictional claims in published maps and institutional affiliations.

(C) 2020 by the authors. Licensee MDPI, Basel, Switzerland. This article is an open access article distributed under the terms and conditions of the Creative Commons Attribution (CC BY) license (http://creativecommons.org/licenses/by/4.0/). 